\title{
REVISIÓN DE LAS PRINCIPALES INVESTIGACIONES SOBRE RESPONSABILIDAD SOCIAL CORPORATIVA Y REPUTACIÓN
}

\section{REVIEW OF THE MAIN INVESTIGATIONS ON CORPORATE SOCIAL RESPONSIBILITY AND REPUTATION}

Isadora Sánchez-Torné (Universidad de Sevilla) ${ }^{1}$

Juan Carlos Morán-Álvarez (Universidad de Sevilla) ${ }^{2}$

José Ángel Pérez-López (Universidad de Sevilla) ${ }^{3}$

\section{Resumen:}

Las actuaciones de las empresas, como agentes económicos partes de una comunidad, influyen en el bienestar de la sociedad. Es por ello que, además de realizar su actividad productiva esta debe ser socialmente responsable. Se ha evidenciado que las actuaciones de Responsabilidad Social Corporativa (RSC en adelante) son esenciales en la construcción de la Reputación de las empresas. En las últimas décadas ha aumentado el interés de la comunidad científica y profesional por determinar la influencia de la RSC y la Reputación en diferentes ámbitos de la empresa. Esta investigación muestra a los principales investigadores, revistas y artículos sobre estas materias. Para ello se ha empleado Web of Science como fuente de información para descargar los informes de citas y se ha realizado un análisis de la tendencia de la producción científica, citas, revistas, autorías y líneas de investigación. Entre las principales conclusiones destaca que las investigaciones en RSC y Reputación es de interés creciente y todavía está en fase de expansión. Existen revistas especializadas en temas sobre RSC y Reputación, pero en su mayoría publican en inglés y son de nacionalidad inglesa y americana. Los autores europeos y en especial los españoles (Universidad de Cantabria y Salamanca) ocupan un puesto de relevancia en la materia. Las principales líneas de investigación indican que la RSC sincera es un elemento clave en la construcción de la Reputación; así mismo, atrae y retiene el talento. Por último, se destaca la importancia las acciones de marketing dirigidas a informar sobre las RSC a los agentes de interés.

Palabras clave: Responsabilidad Social Empresarial, Reputación, Empresa, Ética. Códigos JEL: M14, JO.

\footnotetext{
Abstract:

1 isanchez6@us.es, Universidad de Sevilla.

2 jcmoran@us.es, Universidad de Sevilla.

3 jangel@us.es, Universidad de Sevilla.

Recibido: 5 de abril de 2020. Aceptado: 25 de junio de 2020.
}

The actions of companies, as economic agents integrated into a community, influence the well-being of society. That is why, in addition to carrying out its productive activity, it must be socially responsible. It has been shown that the actions of Corporate Social Responsibility (hereinafter CSR) are essential in building the reputation of companies. In the last decades, we have seen an increase in the interest of the scientific and professional community to determine the influence of CSR and Reputation in different areas of the 
company. This research shows the main researchers, magazines and articles on these matters. Thus, Web of Science has been used as the main source of information to download the citations reports, and we have performed an analysis of the trend of scientific production, citations, magazines, authorships and lines of research. Among the main conclusions, it stands out that the topic CSR and Reputation is of growing interest and still in a phase of expansion. There are specialized magazines on CSR and Reputation, but most of them use only sources from English speaking countries (UK and USA) and published in English. European and especially Spanish authors (University of Cantabria and Salamanca) occupy a position of relevance in the matter. The main lines of research indicate that sincere CSR is a key element in building Reputation; likewise, it attracts and retains talent. Finally, the importance of marketing actions aimed at informing stakeholders about CSR is highlighted.

Key words: Social Responsibility, Reputation, Business, Ethic.

JEL Codes: M14, JO, M5

\section{INTRODUCCIÓN}

Las empresas no son simplemente una institución económica, sino que también actúan como agentes sociales cuyas actuaciones influyen en el bienestar de la comunidad (Boccia y Sarnacchiaro, 2018). La sociedad espera que las empresas generen valor para sus inversores y, además, que sus actuaciones sean socialmente responsables (Aramburu y Pescador, 2019). En 2001, la Comisión Europea define en el libro verde el concepto de Responsabilidad Social de las empresas como «la integración voluntaria, por parte de las empresas, de las preocupaciones sociales y medioambientales en sus operaciones comerciales y sus relaciones con sus interlocutores» ${ }^{4}$. Dentro de este concepto se destacan dos ideas: 1) son actividades realizadas con el fin de contribuir a resolver o paliar los problemas ambientales, velar por los derechos humanos, fomentar el bienestar de los trabajadores, garantizar una gobernanza ética, participativa y transparente; 2) carácter de voluntariedad, pues implica ir más allá de lo que ley obliga.

Diversos investigadores destacan la influencia positiva de la RSC en la Reputación ${ }^{5}$ de las empresas (Aguilera-Caracuel y Guerrero-Villegas, 2018). Asimismo, Leiva, Ferrero y Calderón (2016), en su análisis bibliométrico sobre ética empresarial, hallaron que la Reputación Corporativa emplea la RSC para lograr que las empresas sean éticas en su comportamiento.

La definición de Reputación Empresarial ofrecida por Fombrun (1996, p.72) resulta ser una de la más empleada por la comunidad científica: "una representación perceptiva de las acciones pasadas y las perspectivas futuras de una empresa que describe el atractivo general de la empresa para todos sus componentes clave en comparación con otros rivales principales". Autores, como Toro y Pavia (2019), recogen en su investigación que la Reputación Corporativa ha sido identificada como un valor intangible que se asocia con: Ética, Sostenibilidad, Responsabilidad (Griffin, 2008); Liderazgo, Innovación,

\footnotetext{
${ }^{4}$ Comunicación de la Comisión relativa a la responsabilidad social de las empresas: una contribución empresarial al desarrollo sostenible /* COM/2002/0347 final */ https://eurlex.europa.eu/LexUriServ/LexUriServ.do?uri=CELEX:52002DC0347:ES:HTML (01/02/2020)

${ }^{5}$ Se empleará el concepto Reputación como alusión a la Reputación de las Empresas. Por ello, en este contexto, Reputación Empresarial, Reputación Corporativa y Reputación serán sinónimos.
} 
Responsabilidad Social (Marquina, Arellano y Velásquez, 2014), Transparencia, Rendición de Cuentas (Cagin, 2018), entre otros muchos más.

Una buena valoración de la Reputación de una empresa lleva consigo una serie de beneficios, entre los que destacan el aumenta su grado de lealtad y satisfacción de los clientes (Kim y Kim, 2017), influye en el grado de compromiso y con ello su desempeño laboral de los trabajadores (Almeida y Coelho, 2019), fortalece la lealtad de sus inversores, influye en su grado de satisfacción (Helm, 2007), refuerza la relación con los proveedores (Bennett y Gabriel, 2001).

Tras realizar una revisión de la literatura sobre artículos publicados entre 2000 y 2013, los autores Aksak, Ferguson y Duman (2016) postularon que la responsabilidad social parece ser un componente de la reputación corporativa. Además, se ha observado que las principales técnicas de medición de la Reputación, tales como The Global Most Admired Companies (publicado en Fortune), Review 200 (publicado en Fast Eastern Economic Review), Britain's Most Admired Companies (en Management Today), Reputation Quotient (Wall Street Journal), World Most Respected Companies (Financial Times) y Merco (Cinco Días), han incorporado dimensiones relacionadas con la RSC. Los investigadores Melo y Garrido-Morgado (2012) destacaron que las actuaciones en RSC son las vías más eficientes para construir una buena reputación empresarial.

En todos los campos de estudios, con independencia de la disciplina, se realizaron periódicamente investigaciones bibliométricas ya que son de gran importancia para contextualizar y servir de marco de referencia. Concretamente en relación con la temática de investigación RSC y Reputación se encuentran las investigaciones de Gómez-García (2008) sobre la relación entre la RSC y los resultados financieros; los autores Aksak, Ferguson y Duman (2016) realizaron una revisión de la literatura para estudiar el vínculo entre la Reputación corporativa y la responsabilidad social y más recientemente; MorenoFernández y Fuentes-Lara (2019) analiza el vínculo entre participación de los agentes interesados y las redes sociales destacando la importancia de la RSC y la Reputación.

Ha quedado patente la intrínseca relación entre la RSC y la Reputación, por ello muchos artículos de RSC abarcaron en mayor o menor medida las implicaciones sobre este segundo concepto. En los últimos años se ha incrementado el interés tanto de investigadores como de profesionales en la RSC, lo que ha provocado en aumento de la producción científica (Bae et al., 2020). Debido a su vínculo con varias de las dimensiones que engloba la Reputación, el crecimiento de estas investigaciones ha sido paralelo. Así pues, los análisis bibliométicos son idóneos para delimitar un gran volumen de producción científica (Arguimbau et al., 2013). De ahí la necesidad que cubre este artículo al realizar un análisis bibliomético con los siguientes objetivos:

1) Determinar si la temática de investigación RSC y Reputación es de interés creciente para la comunidad científica.

2) Mostrar las principales revistas que atienden a publicaciones sobre RSC y Reputación, delimitando el idioma empleado y zona geográfica.

3) Presentar las personas investigadoras más relevantes sobre RSC y Reputación, analizado su volumen de publicaciones, citas, país y universidades desde una perspectiva de género.

4) Exponer los hallazgos de aquellos artículos con mayor volumen de citas.

5) Exponer las investigaciones en RSC y Reputación publicadas en 2018 y 2019 más citadas.

Este estudio resulta de gran interés y utilidad ya que se configura como una herramienta de trabajo para la comunidad científica, puesto que permite a las personas 
investigadoras sobre RSC y Reputación alcanzar una visión global y sintética sobre la temática de investigación.

En primer lugar, se describe la metodología empleada en la investigación, posteriormente se detallan los resultados empezando desde los más general hasta lo particular (revistas, autores y artículos), finalmente de exponen las principales conclusiones.

\section{METODOLOGÍA}

Con el fin de alcanzar los objetivos propuesto se decidió emplear la base de datos Web of Science (WOS en adelante), la cual ha sido puesta en valor por autores como Rueda et al. (2007) y Cobo et al. (2011).

Las palabras elegidas para la ecuación de búsqueda y los parámetros para su refinado fueron:

TEMA: (corporate social responsibility and reputation)

Refinado por: tipos de documentos $=$ (article)

Período de tiempo=1900-2019. Índices=SCI-EXPANDED, SSCI, A\&HCI, CPCIS, CPCI-SSH, BKCI-S, BKCI-SSH, ESCI, CCR-EXPANDED, IC.

El resultado fue revisado para evitar los falsos positivos y duplicados. Con ello se constató que los artículos analizados estaban encuadrados en el objeto de estudio. Esta búsqueda se realizó el 10 de enero de 2020, así que se acotó la temporalidad de búsqueda entre 1993 (año del primer artículo publicado sobre la relación entre RSC y reputación) a 2019. Finalmente, el volumen total de resultados analizados alcanzó 1570 artículos. Para el tratamiento estadístico de los informes de citas de los artículos se empleó la hoja de cálculo Microsoft Excel. Para extraer una información lo más rigurosa posible se aplicó un procedimiento de análisis y se identificaron los elementos necesarios para conocer la producción científica (Pritchard, 1969), los cuales se detallan en la tabla 1. 


\section{TABLA 1: TIPOS DE ANÁLISIS Y ELEMENTOS ESTUDIADOS SOBRE LA PRODUCCIÓN CIENTÍFICA EN RSC Y REPUTACIÓN}

\begin{tabular}{|c|c|}
\hline Estructura & $\begin{array}{l}\text { Análisis } \\
\end{array}$ \\
\hline $\begin{array}{l}\text { Volumen total } \\
\text { artículos y } \\
\text { citas. }\end{array}$ & $\begin{array}{l}\text { Ley de Crecimiento Exponencial de la Investigación Científica de Price } \\
\text { (Fernandez-Cano, Torralbo y Vallejo, 2004). Determina que el } \\
\text { crecimiento de la información científica es exponencial y se divide en } 3 \\
\text { etapas: 1) fase preliminar caracterizada por pequeños incrementos; 2) fase } \\
\text { de crecimiento exponencial; 3) fase de desarrollo inalterable. }\end{array}$ \\
\hline \multirow{5}{*}{$\begin{array}{l}\text { Análisis de las } \\
\text { revistas. }\end{array}$} & $\begin{array}{l}\text { Ley de dispersión de la literatura Bradford de } 1934 \text { (Ardanuy Baró, 2012), } \\
\text { la cual indica que: si las revistas científicas se ordenan en una secuencia } \\
\text { decreciente de productividad de artículos sobre un campo específico, éstas } \\
\text { pueden dividirse en un núcleo de revistas que abordan en particular el } \\
\text { tema (núcleo de Bradford) y varios grupos o zonas que contienen } \\
\text { aproximadamente el mismo número de artículos que el núcleo. }\end{array}$ \\
\hline & $\begin{array}{l}\text { Volumen de publicaciones sobre la temática de investigación objeto de } \\
\text { estudio. }\end{array}$ \\
\hline & Temática. \\
\hline & País. \\
\hline & Frecuencia de publicación. \\
\hline \multirow{5}{*}{$\begin{array}{l}\text { Análisis de los } \\
\quad \text { autores. }\end{array}$} & Número de publicaciones. \\
\hline & Citas. \\
\hline & País. \\
\hline & Género. \\
\hline & $\begin{array}{l}\text { Índice de productividad personal: ley de Lotka de } 1926 \text { (Ardanuy Baró, } \\
\text { 2012). El cual propone que un grupo reducido de autores publican la } \\
\text { mayor parte de las investigaciones relevantes en un tema. }\end{array}$ \\
\hline \multirow{8}{*}{$\begin{array}{l}\text { Análisis de los } \\
\text { artículos }\end{array}$} & Número de autoras y autores. \\
\hline & Año de publicación. \\
\hline & Número de citas. \\
\hline & Revista. \\
\hline & Lugar de la investigación y muestra empleada. \\
\hline & Tratamiento estadístico. \\
\hline & Conclusiones. \\
\hline & Relación entre la RSC y la Reputación. \\
\hline
\end{tabular}

\section{RESULTADOS}

El análisis de los resultados sigue la siguiente estructura: 1) evolución de la productividad anual, 2) análisis de las revistas, 3) análisis de los autores, 4) análisis de los artículos.

\subsection{Evolución de la productividad anual}

La comunidad científica comenzó a investigar sobre RSC y Reputación en 1993, con el artículo titulado An investigation of corporate social responsibility reputation and economic performance de los autores Herremans, Akathaporn y McInnes. El volumen de artículos fue incrementándose ligeramente hasta 2006 (ver figura 1), año en que comenzó un auge. La evolución de las publicaciones se ajusta a una ecuación exponencial con un $\mathrm{R}^{2}$ elevado $\left(\mathrm{R}^{2}=0,912\right)$. Esto indica que encaja con la ley de crecimiento exponencial plateada por Price para producción científica. Concretamente se sitúa en fase de 
crecimiento exponencial, es decir la temática es de actualidad e interés científico (Fernandez-Cano et al., 2004).

\section{FIGURA 1: EVOLUCIÓN DE LA PRODUCCIÓN CIENTÍFICA}

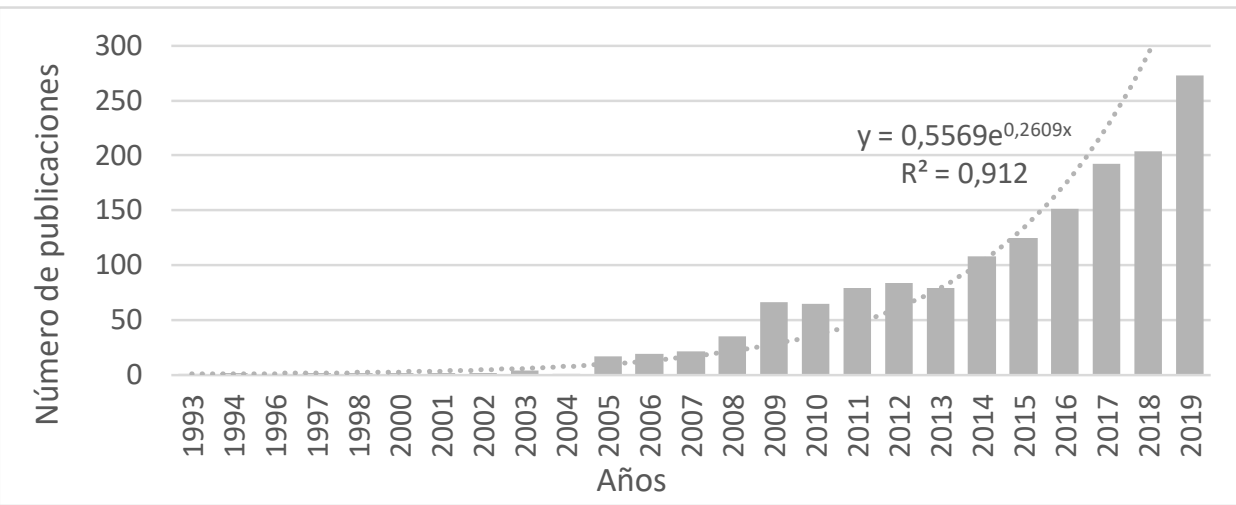

Fuente: Elaboración propia a partir de los datos de WOS (enero 2020).

El número de citas que han recibido los artículos que analizan la RSC y Reputación se han ido incrementando especialmente desde 2006 (figura 2). Este incremento ha presentado una tendencia exponencial y se ajusta con un $\mathrm{R}^{2}(0,9791)$ muy elevado.

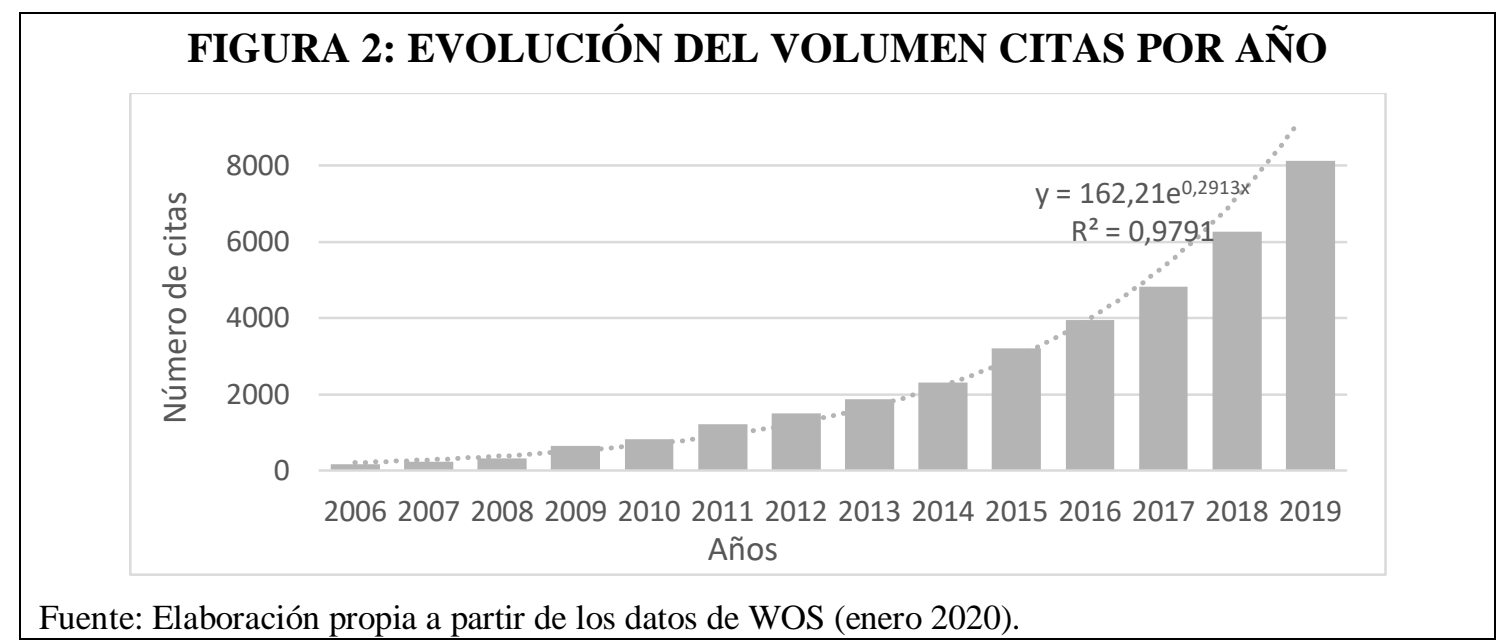

\subsection{Análisis de las revistas}

En la figura 3 se muestran ordenadas (de mayor a menor) el número de revistas en función del volumen de artículos publicados en cada uno sobre RSC y Reputación. Esto dio como resultado una gráfica que exhibe una trayectoria ajustada a un modelo exponencial con un $\mathrm{R}^{2}$ elevado (0,9547). El 63,32 por cien de las revistas solo publicó un artículo relacionado con la materia. Por otro lado, la revista Journal of Business Ethics abarcó el mayor volumen de publicaciones (151), le siguen: Sustainability con 63, Corporate Social Responsibility and Environmental Management con 43, Corporate Reputation Review con 40, Social Responsibility Journal con 38 (tabla 2). Con estos resultados se comprueba que se cumple Ley de Dispersión de Bradford, puesto que se constata que un volumen considerable de fuentes de publicación que solo poseen un 
artículo cada una, mientras que un número escaso de publicaciones abarca el mayor número de artículos.

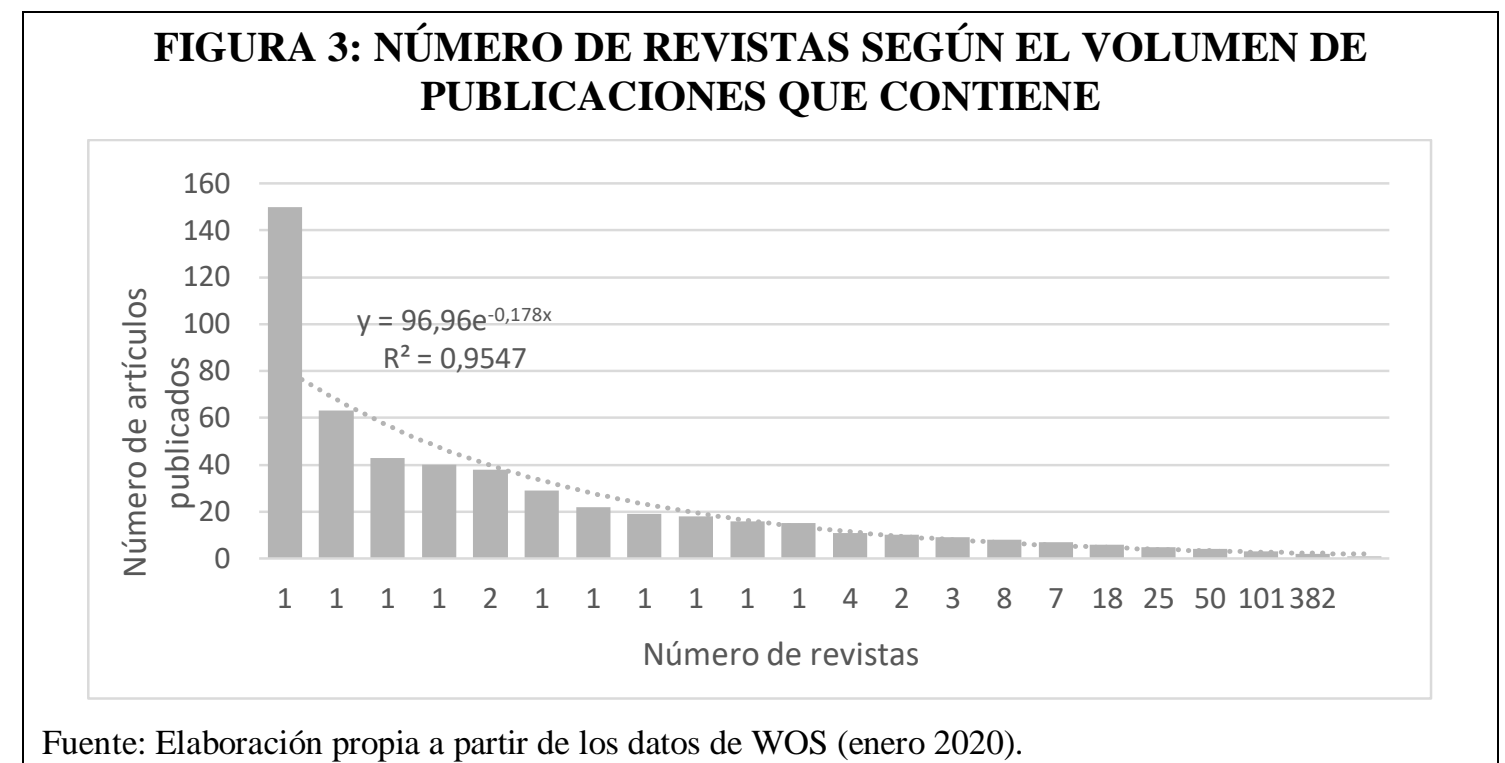

En la tabla 2 se presentan las revistas con más de 10 publicaciones sobre la temática de investigación entre 1993 y 2019 por volumen de citas ${ }^{6}$ recibidas sobre los artículos analizados y otras características de las mismas. Mayoritariamente las revistas pertenecen a entidades americanas o inglesas. Se puede comprobar que no siempre coincide que las revistas con mayor cantidad de publicaciones tengan también más citas, así tenemos dos situaciones:

- Revistas con alto volumen de publicaciones y citas: Journal of Business Ethics (151 publicaciones y 8991 citas), Corporate Reputation Review (40 publicaciones y 796 citas), Corporate Social Responsibility and Environmental Management (43 publicaciones y 778 citas).

- Revistas con reducido volumen de publicaciones, pero con alto número de citas: Strategic Management Journal (11 publicaciones y 929 citas), Journal of the Academy of Marketing Science (10 publicaciones y 853 citas), Journal of Management Studies (10 publicaciones y 846 citas), Journal of Business Research (22 publicaciones y 762 citas).

- Revistas con elevado número de publicaciones y no de citas: Sustainability (63 publicaciones y 256 citas), Social Responsibility Journal (38 publicaciones y 234 citas).

Para determinar qué revistas son las que tienen más interés en RSC y Reputación en la actualidad, se ha presentado la tabla 3 , donde se presentan las revistas que más artículos han publicado en los últimos 5 años sobre la temática de investigación. Journal of Business Ethics sigue siendo la revista que más ha publicado (69) y mayor volumen de citas ha recibido sus artículos (811). En otros casos, las revistas se han decantado por esta temática más recientemente, así, se comprueba que:

\footnotetext{
${ }^{6}$ Las revistas están ordenadas de mayor a menor número de citas, y con esos resultados se ha establecido el criterio para comentar si es elevado o no su volumen
} 
- 1) De las 22 publicaciones que recoge Journal of Business Research, 15 son en los últimos 5 años (379 citas).

-2) De las 43 publicaciones que recoge Corporate Social Responsibility and Environmental Management, 36 son en los últimos 5 años (245 citas).

- De las 40 publicaciones que recoge Corporate Reputation Review, 20 son en los últimos 5 años (85 citas).

- De las 38 publicaciones que recoge Social Responsibility Journal, 21 son de los últimos 5 años (62 citas).

- Las 63 publicaciones de Sustainability recogidas en la tabla de 1993-2019 pertenecen a los últimos 5 años.

Al focalizar el análisis en los últimos 5 años, aparecen otras revistas con alto volumen de publicación sobre RSC y Reputación, como son: Business Strategy and The Environment (14 artículos y 141 citas), Journal of Cleaner Production (15 artículos y 137 citas), Public Relations Review (18 artículos, 102 citas), Corporate Communications (16 artículos y 83 citas)

Finalmente, todas las revistas presentan un factor de impacto elevado y se ubican en las categorías de empresa, gestión, ética, economía y medio ambiente. 


\begin{tabular}{|c|c|c|c|c|c|}
\hline \multicolumn{6}{|c|}{$\begin{array}{l}\text { TABLA 2: REVISTAS CON MAYOR NÚMERO DE ARTÍCULOS } \\
\text { PUBLICADOS SOBRE RSC Y REPUTACIÓN ENTRE } 1993 \text { Y } 2019 \text { (10 } 0 \\
\text { MÁS ARTÍCULOS DE LA TEMÁTICA DE INVESTIGACIÓN) }\end{array}$} \\
\hline Revistas & $\begin{array}{l}\mathbf{N}^{0} \text { de citas } \\
\text { artículos } \\
\text { RSC y RE }\end{array}$ & $\begin{array}{l}\mathbf{N}^{\mathbf{0}} \\
\text { artículos } \\
\text { RSC y RE }\end{array}$ & $\begin{array}{c}\text { Temática de la } \\
\text { revista }\end{array}$ & $\begin{array}{l}\text { Frecuencia } \\
\text { publicación }\end{array}$ & País \\
\hline $\begin{array}{l}\text { Journal of Business } \\
\text { Ethics }\end{array}$ & 8991 & 151 & Ética, Negocio & 28 pub/año & $\begin{array}{l}\text { Países } \\
\text { Bajos }\end{array}$ \\
\hline $\begin{array}{l}\text { Strategic Management } \\
\text { Journal }\end{array}$ & 929 & 11 & Gestión, Negocios & 13 pub/año & $\begin{array}{l}\text { Estados } \\
\text { Unidos }\end{array}$ \\
\hline $\begin{array}{l}\text { Journal of the Academy } \\
\text { of Marketing Science }\end{array}$ & 853 & 10 & Negocios & 6 pub/año & $\begin{array}{l}\text { Estados } \\
\text { Unidos }\end{array}$ \\
\hline $\begin{array}{l}\text { Journal of Management } \\
\text { Studies }\end{array}$ & 846 & 10 & Gestión, Negocios & 8 pub/año & Inglaterra \\
\hline $\begin{array}{l}\text { Corporate Reputation } \\
\text { Review }\end{array}$ & 796 & 40 & $\begin{array}{l}\text { Negocios, Gestión y } \\
\text { Contabilidad } \\
\text { Estrategia } \\
\text { Internacional de } \\
\text { Gestión }\end{array}$ & 4 pub/año & Inglaterra \\
\hline $\begin{array}{l}\text { Corporate Social } \\
\text { Responsibility and } \\
\text { Environmental } \\
\text { Management }\end{array}$ & 778 & 43 & $\begin{array}{l}\text { Gestión, Negocios, } \\
\text { Medio ambiente }\end{array}$ & 66 pub/año & Inglaterra \\
\hline $\begin{array}{l}\text { Journal of Business } \\
\text { Research }\end{array}$ & 762 & 22 & Negocios & 12 pub/año & $\begin{array}{l}\text { Estados } \\
\text { Unidos }\end{array}$ \\
\hline $\begin{array}{l}\text { Corporate } \\
\text { Communications }\end{array}$ & 600 & 29 & $\begin{array}{l}\text { Negocios, Gestión, } \\
\text { Contabilidad, } \\
\text { Relaciones } \\
\text { Industriales, } \\
\text { Comportamiento } \\
\text { Organizacional y } \\
\text { Recursos Humanos }\end{array}$ & 4 pub/año & Inglaterra \\
\hline Management Decision & 528 & 19 & Gestión, Negocios & 10 pub/año & Inglaterra \\
\hline $\begin{array}{l}\text { Public Relations } \\
\text { Review }\end{array}$ & 448 & 29 & $\begin{array}{l}\text { Negocios, } \\
\text { Comunicación } \\
\end{array}$ & 5 pub/año & $\begin{array}{l}\text { Estados } \\
\text { Unidos } \\
\end{array}$ \\
\hline Business \& Society & 436 & 18 & Negocios & 8 pub/año & $\begin{array}{l}\text { Estados } \\
\text { Unidos }\end{array}$ \\
\hline Sustainability & 256 & 63 & $\begin{array}{l}\text { Energía, Ciencia } \\
\text { ambiental, Ciencia } \\
\text { social }\end{array}$ & 12 pub/año & Suiza \\
\hline $\begin{array}{l}\text { International Journal of } \\
\text { bank marketing }\end{array}$ & 248 & 10 & Negocios & 7 pub/año & Inglaterra \\
\hline $\begin{array}{l}\text { business strategy and } \\
\text { the environment }\end{array}$ & 243 & 15 & $\begin{array}{l}\text { Gestión, Negocios, } \\
\text { Estudios } \\
\text { Ambientales }\end{array}$ & 8 pub/Año & $\begin{array}{l}\text { Estados } \\
\text { Unidos }\end{array}$ \\
\hline $\begin{array}{l}\text { social responsibility } \\
\text { journal }\end{array}$ & 234 & 38 & $\begin{array}{l}\text { Negocios, } \\
\text { administración y } \\
\text { contabilidad }\end{array}$ & 8 pub/año & Inglaterra \\
\hline $\begin{array}{l}\text { journal of cleaner } \\
\text { production }\end{array}$ & 188 & 16 & $\begin{array}{l}\text { Ciencias } \\
\text { medioambientales } \\
\text { Ciencia y tecnología } \\
\text { sostenible } \\
\text { Ingeniería }\end{array}$ & 30 pub/año & Inglaterra \\
\hline $\begin{array}{l}\text { journal of product and } \\
\text { brand management }\end{array}$ & 148 & 10 & Gestión, Negocios & 7 pub/año & Inglaterra \\
\hline $\begin{array}{l}\text { business ethics-a } \\
\text { european review }\end{array}$ & 56 & 10 & Negocios, Ética & 4 pub/año & $\begin{array}{l}\text { Estados } \\
\text { Unidos }\end{array}$ \\
\hline
\end{tabular}




\begin{tabular}{|c|c|c|c|c|c|}
\hline \multicolumn{6}{|c|}{$\begin{array}{l}\text { TABLA 3: REVISTAS CON MAYOR NÚMERO DE ARTÍCULOS } \\
\text { PUBLICADOS SOBRE RSC Y REPUTACIÓN ENTRE } 2015 \text { Y } 2019 \text { (10 } 0 \\
\text { MÁS ARTÍCULOS DE LA TEMÁTICA DE INVESTIGACIÓN) }\end{array}$} \\
\hline Revistas & $\begin{array}{l}\mathbf{N}^{\circ} \text { de citas } \\
\text { artículos } \\
\text { RSC y RE }\end{array}$ & $\begin{array}{c}\mathbf{N}^{\mathbf{0}} \\
\text { artículos } \\
\text { RSC y RE } \\
\end{array}$ & $\begin{array}{c}\text { Temática de la } \\
\text { revista }\end{array}$ & $\begin{array}{l}\text { Frecuencia } \\
\text { publicación }\end{array}$ & País \\
\hline $\begin{array}{l}\text { Journal of Business } \\
\text { Ethics }\end{array}$ & 811 & 69 & Ética, Negocio & 28 pub/año & $\begin{array}{r}\text { Países } \\
\text { Bajos }\end{array}$ \\
\hline $\begin{array}{l}\text { Journal of Business } \\
\text { Research }\end{array}$ & 379 & 15 & Negocios & 12 pub/año & $\begin{array}{r}\text { Estados } \\
\text { Unidos }\end{array}$ \\
\hline Sustainability & 256 & 63 & $\begin{array}{r}\text { Energía, Ciencia } \\
\text { ambiental, } \\
\text { Ciencia social }\end{array}$ & 12 pub/año & Suiza \\
\hline $\begin{array}{l}\text { Corporate Social } \\
\text { Responsibility and } \\
\text { Environmental } \\
\text { Management }\end{array}$ & 245 & 36 & $\begin{array}{r}\text { Gestión, } \\
\text { Negocios, Medio } \\
\text { ambiente }\end{array}$ & 66 pub/año & Inglaterra \\
\hline $\begin{array}{l}\text { Business Strategy and } \\
\text { the Environment }\end{array}$ & 141 & 14 & $\begin{array}{r}\text { Gestión, } \\
\text { Negocios } \\
\text { Estudios } \\
\text { Ambientales }\end{array}$ & 8 pub/año & $\begin{array}{r}\text { Estados } \\
\text { Unidos }\end{array}$ \\
\hline $\begin{array}{l}\text { Journal of Cleaner } \\
\text { Production }\end{array}$ & 137 & 15 & \begin{tabular}{|r|} 
Ciencias \\
medioambientales \\
Ciencia y \\
tecnología \\
sostenible \\
Ingeniería
\end{tabular} & 30 pub/año & Inglaterra \\
\hline Public Relations Review & 102 & 18 & $\begin{array}{r}\text { Negocios, } \\
\text { Comunicación }\end{array}$ & & $\begin{array}{r}\text { Estados } \\
\text { Unidos }\end{array}$ \\
\hline Business \& Society & 87 & 11 & Negocios & 8 pub/año & $\begin{array}{r}\text { Estados } \\
\text { Unidos }\end{array}$ \\
\hline $\begin{array}{l}\text { Corporate Reputation } \\
\text { Review }\end{array}$ & 85 & 20 & $\begin{array}{r}\text { Negocios, } \\
\text { Gestión y } \\
\text { Contabilidad } \\
\text { Estrategia } \\
\text { Internacional de } \\
\text { Gestión }\end{array}$ & 4 pub/año & Inglaterra \\
\hline $\begin{array}{l}\text { Corporate } \\
\text { Communications }\end{array}$ & 83 & 16 & $\begin{array}{r}\text { Negocios, } \\
\text { Gestión y } \\
\text { Contabilidad } \\
\text { Relaciones } \\
\text { Industriales } \\
\text { Comportamiento } \\
\text { Organizacional y } \\
\text { Gestión de } \\
\text { Recursos } \\
\text { Humanos }\end{array}$ & 4 pub/año & Inglaterra \\
\hline $\begin{array}{l}\text { Social Responsibility } \\
\text { Journal }\end{array}$ & 62 & 21 & $\begin{array}{r}\text { Negocios, } \\
\text { administración y } \\
\text { contabilidad }\end{array}$ & 8 pub/año & Inglaterra \\
\hline
\end{tabular}

Fuente: Elaboración propia a partir de los datos de WOS (enero 2020). 
Algunos de los artículos recogidos en la base de datos extraída de WOS fueron publicados en revistas de habla hispana:

- Revistas del ámbito de la comunicación: Tripodos, Revista Internacional de Relaciones Públicas, Redu-Revista de docencia Universitaria, Profesional de la Información, Revista Mediterránea de Comunicación, Revista Latina de Comunicación Social.

- Revista del campo de empresa y economía: Estudios Gerenciales, Revista Universidad empresa, Retos-Revista de Ciencias de la Administración y Economía, Dimensión Empresarial, Revista de Contabilidad, Revista Cicag, CIRIEC-Espana revista de Economía publica social y cooperativa, Revista Perspectiva Empresarial, Revista de Estudios Empresariales-Segunda época, REVESCO-Revista de Estudios Cooperativos.

El idioma empleado en los artículos analizados (tabla 4) fue principalmente el inglés (94,27por cien). El español se sitúa en segundo puesto con el 4,23 por cien.

\begin{tabular}{l} 
TABLA 4: IDIOMA DE LAS PUBLICACIONES \\
\begin{tabular}{|c|r|r|}
\hline Idioma & Número & Porcentaje \\
\hline Inglés & 1449 & 94,27 por cien \\
\hline Español & 65 & 4,23 por cien \\
\hline Turco & 7 & 0,46 por cien \\
\hline Lituano & 3 & 0,20 por cien \\
\hline Portugués & 3 & 0,20 por cien \\
\hline Chino & 2 & 0,13 por cien \\
\hline Croata & 2 & 0,13 por cien \\
\hline Ruso & 2 & 0,13 por cien \\
\hline Holandés & 1 & 0,07 por cien \\
\hline Francés & 1 & 0,07 por cien \\
\hline Italiano & 1 & 0,07 por cien \\
\hline No especificado & 1 & 0,07 por cien \\
\hline
\end{tabular} \\
Fuente: Elaboración propia a partir de los datos de WOS (enero 2020 ). \\
\hline
\end{tabular}

En cuanto a los países que publican sobre RSC y Reputación (figura 4), se evidenció que la mayoría de las referencias provienen de los Estados Unidos (21,15 por cien). Dentro de la Unión Europea destacaron: España (10,65 por cien), Alemania (3,24 por cien) y Países Bajos (3,04 por cien). Después de España, el tercer país más productivo fue Reino Unido (7,26 por cien). 


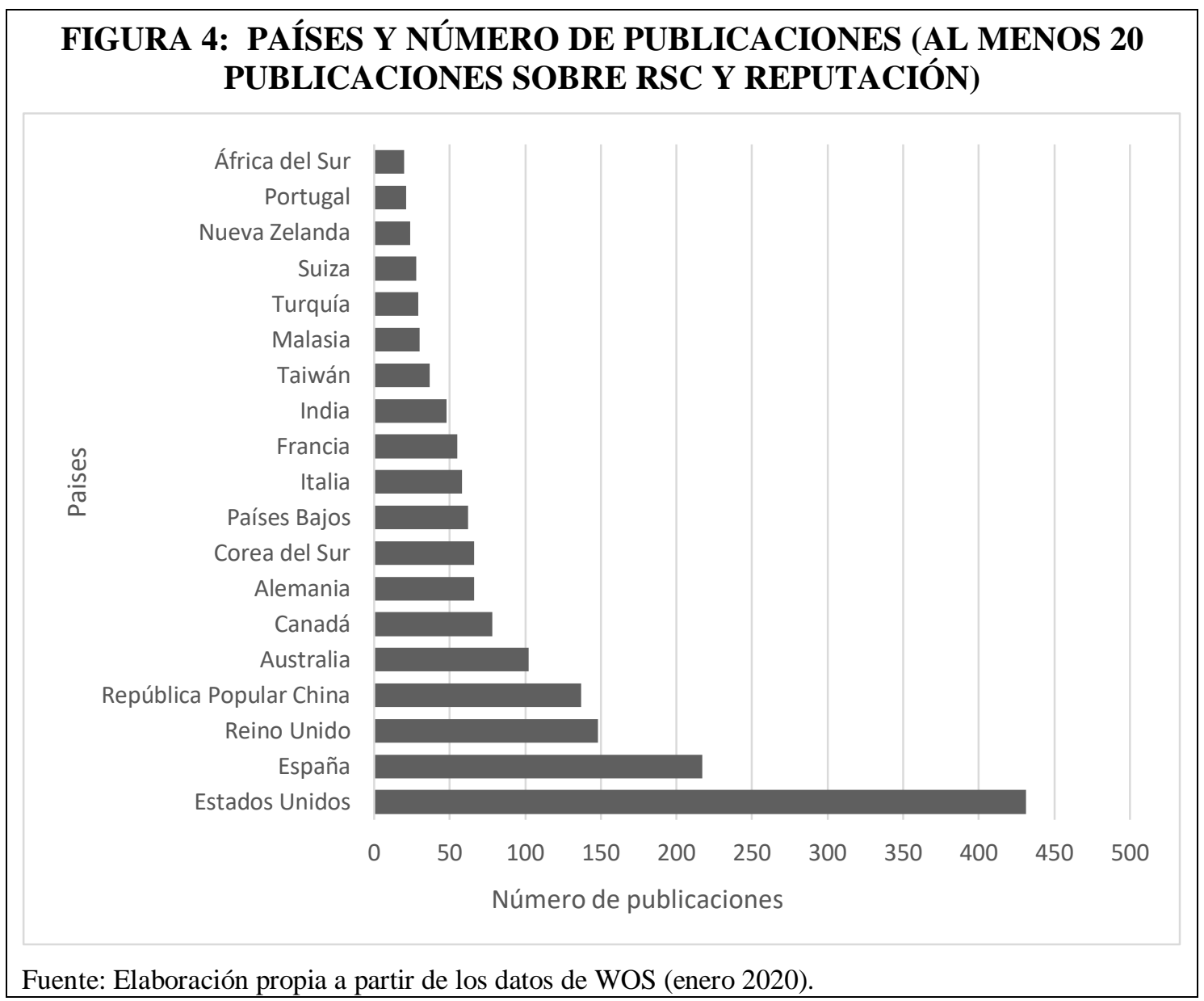

En consonancia con los resultados evidenciados en la figura 4, la tabla 5 muestra que Estados Unidos (13) fue el territorio con mayor cantidad de Universidades que han publicado sobre la temática de investigación analizado, le sigue España (7), China (5) e Inglaterra (5). Dentro de las 5 organizaciones más productivas en esta temática, se evidencia que en la Universidad de Cantabria fue la organización con mayor producción científica (19), en segundo lugar, se encuentra la Universidad Estatal de Pensilvania (18), y posteriormente las universidades de Salamanca (18), Granada (14) y Florida (13).

A tenor de estos datos, se pone de manifiesto que las universidades españolas son el referente europeo en las investigaciones sobre RSC y Reputación Empresarial. 
TABLA 5: INSTITUCIONES A LA QUE PERTENECES LOS AUTORES (MÍNIMO 10 PUBLICACIONES)

\begin{tabular}{|l|c|}
\hline \multicolumn{1}{|c|}{ Universidades } & $\begin{array}{c}\text { Volumen de } \\
\text { publicaciones }\end{array}$ \\
\hline Universidad de Cantabria (España) & 19 \\
\hline Universidad Estatal de Pensilvania (Estados Unidos) & 18 \\
\hline Universidad de Salamanca (España) & 18 \\
\hline Universidad de Granada (España) & 14 \\
\hline Universidad Estatal de Florida (Estados Unidos) & 13 \\
\hline Universidad de Indiana Bloomington (Estados Unidos) & 13 \\
\hline Universidad Complutense (España) & 13 \\
\hline Universidad de Florida (Estados Unidos) & 13 \\
\hline Universidad de Reading (Inglaterra) & 13 \\
\hline Universidad Erasmo de Róterdam (Países Bajos) & 12 \\
\hline Universidad de Extremadura (España) & 12 \\
\hline Universidad de Misuri (Estados Unidos) & 12 \\
\hline Universidad de Carolina (Estados Unidos) & 12 \\
\hline Universidad Central del Sur (China) & 11 \\
\hline Universidad Politécnica de Hong Kong (China) & 11 \\
\hline Universidad de Georgia (Estados Unidos) & 11 \\
\hline Universidad Simon Fraser (Canadá) & 10 \\
\hline Amsterdam Universidad College (Países Bajos) & 10 \\
\hline Universidad de Bath (Inglaterra) & 10 \\
\hline Universidad de Míchigan (Estados Unidos) & 10 \\
\hline Universidad de Texas (Estados Unidos) & 10 \\
\hline Universidad de Wisconsin-Madison (Estados Unidos) & 10 \\
\hline
\end{tabular}

Fuente: Elaboración propia a partir de los datos de WOS (enero 2020).

\subsection{Análisis de los autores}

En este caso no se cumple la Ley de Lotka ya que el 86,65 por cien de las referencias corresponden a autores que solo han publicado un artículo sobre RSC y Reputación. En otras palabras, el tema objeto de análisis no presentó concentración de publicaciones en un grupo reducido de investigadores (figura 5).

\section{FIGURA 5: VOLUMEN DE PUBLICACIONES SEGÚN NÚMERO DE AUTORES.}

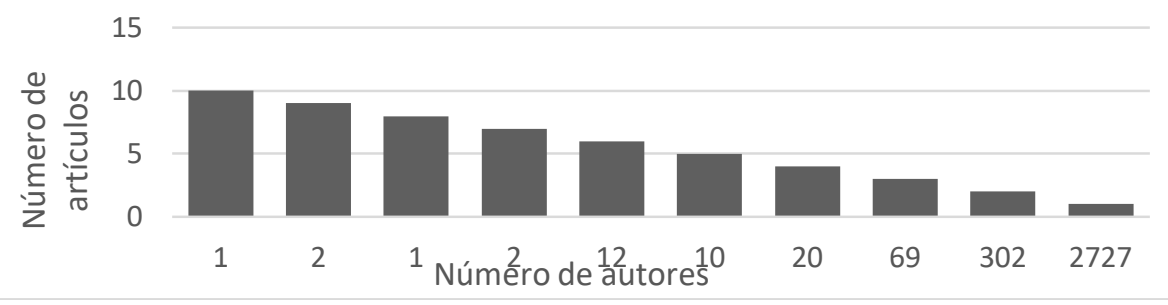

Fuente: Elaboración propia a partir de los datos de WOS (enero 2020). 
En la tabla 6 aparecen los autores y sus principales características como investigadores, que en el periodo de estudios (1993-2019) hayan publicado al menos cinco artículos, esto dio como resultado un total de 28 investigadores.

El autor más prolífero fue John Peloza (10 artículos) de la Universidad de Kentucky (Estados Unidos), además es el tercero que presenta mayor número de citas en los artículos recogidos (412). Los siguientes autores con mayor volumen de publicaciones: Su Lujun de la Universidad Central del Sur en China (9 artículos y 117 citas) Isabel María García Sánchez de la Universidad de Salamanca en España (9 artículos y 196 citas).

Los 6 artículos de Manuel Castelo Branco de la Universidad de Oporto (Portugal) registraron el mayor volumen de citas (804) por autor. Ente ellos destacan los siguientes títulos: Corporate social responsibility and resource-based perspectives (520 citas) y Factors Influencing Social Responsibility Disclosure by Portuguese Companies (239 citas).

Otros investigadores relevantes en la materia en función del número de citas de sus artículos fueron: Stephen Pavelin de la Universidad de Bath en Inglaterra (463), John Peloza de la Universidad de Kentucky en Estados Unidos (412 citas), Mike Pfarrer de la Universidad de Georgia en Estados Unidos (391 citas) y Jo Hoje de la Universidad de Santa Clara en Estados Unidos (302 citas).

Por último, a modo descriptivo resaltamos algunas características de este colectivo de personas autoras en relación a la tabla 6:

- Solo el 41,67 por cien de las personas autoras fueron mujeres (10). Donde 5 de ellas provienen de instituciones españolas y 4 son americanas.

- El 39,86 por cien de los artículos perteneces a mujeres, pero estos solo recibieron el 18,70 por cien de las citas recogidas.

- El 41,67 por cien de los autores perteneces a centros ubicados en la Unión Europea (10).

- Estados Unidos fue el país que recoge más investigadores (9 autores) seguido de España (8 autores).

De los autores recogidos en la tabla 5 aquellos que han sido más productivos en los últimos 5 años fueron: Su Lujun (9 artículos), Isabel María García Sánchez (7 artículos), Dolores Gallardo Vázquez (6 artículos), Andrea Pérez (6 artículos), Shaun R. Swanson (6 artículos), Carme Ferré Pavía (5 artículos), Jaime Guerrero Villegas (5 artículos), Jennifer Martínez Ferrero (5 artículos). 


\section{TABLA 6: PERSONAS AUTORAS CON MAYOR NÚMERO DE PUBLICACIONES ENTRE 1993 Y 2019}

\begin{tabular}{|c|c|c|c|c|c|}
\hline Nombre y apellidos & Sexo & $\begin{array}{c}\mathrm{N}^{\mathbf{0}} \\
\text { artículos } \\
\text { RSC Y } \\
\text { RE }\end{array}$ & $\begin{array}{c}\mathbf{N}^{\circ} \text { citas } \\
\text { artículos } \\
\text { RSC Y RE }\end{array}$ & $\begin{array}{l}\text { Organización a } \\
\text { la que pertenece }\end{array}$ & País \\
\hline $\begin{array}{l}\text { John Peloza } \\
\text { (PELOZA J) }\end{array}$ & Hombre & 10 & 412 & $\begin{array}{l}\text { Universidad de } \\
\text { Kentucky }\end{array}$ & $\begin{array}{l}\text { Estados } \\
\text { Unidos }\end{array}$ \\
\hline Su Lujun (SU L J) & Hombre & 9 & 117 & $\begin{array}{l}\text { Universidad } \\
\text { Central del Sur }\end{array}$ & China \\
\hline $\begin{array}{l}\text { Isabel María García Sánchez } \\
\text { (GARCIA-SANCHEZ IM) }\end{array}$ & Mujer & 9 & 196 & $\begin{array}{l}\text { Universidad de } \\
\text { Salamanca }\end{array}$ & España \\
\hline Jerry Wei (WEI JC) & Hombre & 8 & 31 & $\begin{array}{l}\text { Universidad de } \\
\text { Notre Dame }\end{array}$ & Francia \\
\hline $\begin{array}{l}\text { Xiaochen Angela Zhang } \\
\text { (CHEN XH) }\end{array}$ & Mujer & 7 & 92 & $\begin{array}{l}\text { Universidad de } \\
\text { Kansas }\end{array}$ & EE.UU \\
\hline $\begin{array}{lr}\text { Ladislao Luna } & \text { Sotorrio } \\
\text { (SOTORRIO LL) } & \end{array}$ & Hombre & 7 & 217 & $\begin{array}{l}\text { Universidad } \\
\text { de Cantabria }\end{array}$ & España \\
\hline $\begin{array}{lll}\text { Manuel Castelo } & \text { Branco } \\
\text { BRANCO MC } & \\
\end{array}$ & Hombre & 6 & 804 & $\begin{array}{l}\text { Universidad de } \\
\text { Oporto }\end{array}$ & Portugal \\
\hline $\begin{array}{l}\text { Dolores-Gallardo Vazquez } \\
\text { (GALLARDO-VAZQUEZ D) }\end{array}$ & Mujer & 6 & 12 & $\begin{array}{l}\text { Universidad de } \\
\text { Extremadura }\end{array}$ & España \\
\hline $\begin{array}{l}\text { Carole Hillenbrand } \\
\text { (HILLENBRAND C) }\end{array}$ & Mujer & 6 & 79 & $\begin{array}{l}\text { Universidad de } \\
\text { Edimburgo } \\
\text { y St. Andrews }\end{array}$ & $\begin{array}{l}\text { Estados } \\
\text { Unidos }\end{array}$ \\
\hline Jo Hoje (JO H) & Hombre & 6 & 302 & $\begin{array}{l}\text { Universidad de } \\
\text { Santa Clara }\end{array}$ & \begin{tabular}{|l|} 
Estados \\
Unidos
\end{tabular} \\
\hline Stephen Pavelin (PAVELIN S) & Hombre & 6 & 463 & $\begin{array}{l}\text { Universidad de } \\
\text { Bath }\end{array}$ & Inglaterra \\
\hline Andrea Pérez (PEREZ A) & Mujer & 6 & 34 & $\begin{array}{l}\text { Universidad de } \\
\text { Cantabria }\end{array}$ & España \\
\hline $\begin{array}{l}\text { José Luis Fernández Sánchez } \\
\text { (SANCHEZ JLF) }\end{array}$ & Hombre & 6 & 138 & $\begin{array}{l}\text { Universidad de } \\
\text { Cantabria }\end{array}$ & España \\
\hline $\begin{array}{lcl}\text { Shaun } & \text { R. } & \text { Swanson } \\
\text { (SWANSON SR) } & \\
\end{array}$ & Hombre & 6 & 98 & \begin{tabular}{|l} 
Universidad \\
Carnegie Mellon
\end{tabular} & $\begin{array}{l}\text { Estados } \\
\text { Unidos }\end{array}$ \\
\hline $\begin{array}{l}\text { Carme Ferré Pavía (FERRE- } \\
\text { PAVIA C) }\end{array}$ & Mujer & 5 & 7 & $\begin{array}{l}\text { Universidad } \\
\text { Autónoma de } \\
\text { Barcelona }\end{array}$ & España \\
\hline $\begin{array}{lcc}\text { Jaime } & \text { Guerrero } & \text { Villegas } \\
\text { (GUERRERO-VILLEGAS J) }\end{array}$ & Hombre & 5 & 33 & $\begin{array}{l}\text { Universidad de } \\
\text { Cádiz } \\
\end{array}$ & España \\
\hline $\begin{array}{lcc}\text { Thomas } & \text { A. } & \text { Hemphill } \\
\text { (HEMPHILL TA) } & \end{array}$ & Hombre & 5 & 26 & $\begin{array}{l}\text { Universidad de } \\
\text { Michigan }\end{array}$ & $\begin{array}{l}\text { Estados } \\
\text { Unidos }\end{array}$ \\
\hline Lee Sun Young (LEE SY) & Mujer & 5 & 62 & $\begin{array}{l}\text { Universidad de } \\
\text { Maryland }\end{array}$ & \begin{tabular}{|l} 
Estados \\
Unidos
\end{tabular} \\
\hline $\begin{array}{lcc}\text { Jennifer } & \text { Martínez } & \text { Ferrero } \\
\text { (MARTINEZ-FERRERO J) }\end{array}$ & Mujer & 5 & 78 & $\begin{array}{l}\text { Universidad de } \\
\text { Salamanca }\end{array}$ & España \\
\hline $\begin{array}{ll}\begin{array}{l}\text { Giovanna } \\
\text { (MICHELON G) }\end{array} & \text { Michelon } \\
\end{array}$ & Mujer & 5 & 220 & $\begin{array}{l}\text { Universidad de } \\
\text { Bristol }\end{array}$ & Inglaterra \\
\hline Kevin Money (MONEY K) & Hombre & 5 & 79 & $\begin{array}{l}\text { Universidad de } \\
\text { Reading }\end{array}$ & Inglaterra \\
\hline $\begin{array}{l}\text { Zhengqing } \\
\text { (OUYANG Z) }\end{array}$ & Hombre & 5 & 24 & $\begin{array}{l}\text { Universidad de } \\
\text { Massachusetts }\end{array}$ & Inglaterra \\
\hline Mike Pfarrer (PFARRER MD) & Hombre & 5 & 391 & $\begin{array}{l}\text { Universidad de } \\
\text { Georgia }\end{array}$ & $\begin{array}{l}\text { Estados } \\
\text { Unidos }\end{array}$ \\
\hline Hyejoon Rim (RIM H) & Mujer & 5 & 31 & $\begin{array}{l}\text { Universidad de } \\
\text { Minnesota }\end{array}$ & $\begin{array}{l}\text { Estados } \\
\text { Unidos }\end{array}$ \\
\hline
\end{tabular}

Fuente: Elaboración propia a partir de los datos de WOS y Google Académico (enero 2020). 
Por último, debido al peso de las publicaciones y personas autoras españolas en la temática de investigación RSC y Reputación se ha elaborado la tabla 7, donde se presentan por orden de publicación aquellas que como mínimo poseen 3 artículos. Las Universidades de Cantabria (5) y Salamanca (4) fueron los centros más productivos, y con ello los autores de estas ocuparon puestos predominantes en la tabla. Así pues, destacan, Isabel María García Sánchez de la Universidad de Salamanca fue la autora más productiva (9 artículos y 196 citas) y la tercera el número de citas. Le sigue Ladislao Luna Sotorrio de la Universidad de Cantabria (7 artículos y 217 citas). El 53,85 por cien de las personas autoras fueron mujeres, estas abarcaron el 56,76 por cien de las publicaciones, pero solo supusieron el 40,20 por cien de las citas. Dentro de Andalucía se registran 3 universidades: Granada (2 artículos), Cádiz (1 artículo) y Jaén (1 artículo).

\begin{tabular}{|c|c|c|c|c|}
\hline \multicolumn{5}{|c|}{$\begin{array}{c}\text { TABLA 7: PERSONAS AUTORAS PERTENECIENTE A } \\
\text { ORGANIZACIONES ESPAÑOLAS QUE HAN PUBLICADO AL MENOS } 3 \\
\text { ARTÍCULOS ENTRE } 1993 \text { Y } 2019\end{array}$} \\
\hline Nombre y apellidos & Sexo & $\begin{array}{l}\text { Organización a } \\
\text { la que pertenece }\end{array}$ & $\begin{array}{l}\mathbf{N}^{\circ} \text { artículos } \\
\text { RSC Y RE }\end{array}$ & $\begin{array}{c}\mathrm{N}^{0} \text { citas } \\
\text { artículos } \\
\text { RSC Y RE }\end{array}$ \\
\hline $\begin{array}{l}\text { Isabel María García Sánchez (GARCIA- } \\
\text { SANCHEZ IM) }\end{array}$ & Mujer & $\begin{array}{l}\text { Universidad de } \\
\text { Salamanca } \\
\end{array}$ & 9 & 196 \\
\hline Ladislao Luna Sotorrio (SOTORRIO LL) & Hombre & $\begin{array}{l}\text { Universidad de } \\
\text { Cantabria }\end{array}$ & 7 & 217 \\
\hline $\begin{array}{l}\text { Dolores Gallardo Vazquez (GALLARDO- } \\
\text { VAZQUEZ D) }\end{array}$ & Mujer & $\begin{array}{l}\text { Universidad de } \\
\text { Extremadura } \\
\end{array}$ & 6 & 12 \\
\hline Andrea Pérez (PEREZ A) & Mujer & $\begin{array}{l}\text { Universidad de } \\
\text { Cantabria }\end{array}$ & 6 & 34 \\
\hline $\begin{array}{l}\text { José Luis Fernández Sánchez (SANCHEZ } \\
\text { JLF) }\end{array}$ & Hombre & \begin{tabular}{|l|l} 
Universidad de \\
Cantabria
\end{tabular} & 6 & 138 \\
\hline Elisa Baraibar Díez (DIEZ EB) & Mujer & $\begin{array}{l}\text { Universidad de } \\
\text { Cantabria }\end{array}$ & 6 & 85 \\
\hline Carme Ferré Pavía (FERRE-PAVIA C) & Mujer & $\begin{array}{l}\text { Universidad } \\
\text { Autónoma de } \\
\text { Barcelona }\end{array}$ & 5 & 7 \\
\hline $\begin{array}{l}\text { Jaime Guerrero Villegas (GUERRERO- } \\
\text { VILLEGAS J) }\end{array}$ & Hombre & $\begin{array}{l}\text { Universidad de } \\
\text { Cádiz }\end{array}$ & 5 & 33 \\
\hline $\begin{array}{l}\text { Jennifer Martínez Ferrero (MARTINEZ- } \\
\text { FERRERO J) }\end{array}$ & Mujer & $\begin{array}{l}\text { Universidad de } \\
\text { Salamanca }\end{array}$ & 5 & 78 \\
\hline $\begin{array}{l}\text { Javier Aguilera Caracuel (AGUILERA- } \\
\text { CARACUEL J) }\end{array}$ & Hombre & $\begin{array}{l}\text { Universidad de } \\
\text { Granada }\end{array}$ & 4 & 32 \\
\hline $\begin{array}{l}\mathrm{M}^{\mathrm{a}} \text { Eugenia López-Pérez (LOPEZ-PEREZ } \\
\mathrm{ME} \text { ) }\end{array}$ & Mujer & $\begin{array}{l}\text { Areca Consulting } \\
\text { Group }\end{array}$ & 4 & 32 \\
\hline Tiago Melo (MELO T) & Hombre & $\begin{array}{l}\text { Universidad de } \\
\text { Salamanca }\end{array}$ & 4 & 202 \\
\hline Abel Monfort (MONFORT A) & Hombre & $\begin{array}{l}\text { ESIC Business \& } \\
\text { Marketing School }\end{array}$ & 4 & 5 \\
\hline $\begin{array}{l}\text { María Dolores Odriozola (ODRIOZOLA } \\
\text { MD) }\end{array}$ & Mujer & $\begin{array}{l}\text { Universidad de } \\
\text { Cantabria }\end{array}$ & 4 & 40 \\
\hline Elisa Baraibar (BARAIBAR-DIEZ E) & Mujer & $\begin{array}{l}\text { Universidad de } \\
\text { Cantabria }\end{array}$ & 3 & 35 \\
\hline Paul Capriotti (CAPRIOTTI P) & Hombre & $\begin{array}{l}\text { Universidad } \\
\text { Pública de } \\
\text { Tarragona }\end{array}$ & 3 & 16 \\
\hline $\begin{array}{l}\text { Francisca Castilla-Polo } \\
\text { (CASTILLA-POLO F) }\end{array}$ & Mujer & $\begin{array}{l}\text { Universidad de } \\
\text { Jaén } \\
\end{array}$ & 3 & 8 \\
\hline $\begin{array}{l}\begin{array}{l}\text { Esther de Quevedo Puente } \\
\text { (DE QUEVEDO-PUENTE E) }\end{array} \\
\end{array}$ & Mujer & $\begin{array}{l}\text { Universidad de } \\
\text { Burgos }\end{array}$ & 3 & 39 \\
\hline
\end{tabular}




\begin{tabular}{|l|l|l|r|r|}
\hline $\begin{array}{l}\text { Juan Bautista Delgado García } \\
\text { (DELGADO-GARCIA JB) }\end{array}$ & Hombre & $\begin{array}{l}\text { Universidad de } \\
\text { Burgos }\end{array}$ & 3 & 39 \\
\hline $\begin{array}{l}\text { Jose I. Galan } \\
\text { (GALAN JI) }\end{array}$ & Hombre & $\begin{array}{l}\text { Universidad de } \\
\text { Salamanca }\end{array}$ & 3 & 28 \\
\hline $\begin{array}{l}\text { Juan Piñeiro-Chousa } \\
\text { (PINEIRO-CHOUSA J) }\end{array}$ & Hombre & $\begin{array}{l}\text { Universidad de } \\
\text { Santiago de } \\
\text { Compostela }\end{array}$ & 3 & 46 \\
\hline $\begin{array}{l}\text { Lázaro Rodríguez-Ariza } \\
\text { RODRIGUEZ-ARIZA L) }\end{array}$ & Hombre & $\begin{array}{l}\text { Universidad de } \\
\text { Granada }\end{array}$ & 3 & 8 \\
\hline $\begin{array}{l}\text { M. Isabel Sánchez-Hernández } \\
\text { (SANCHEZ-HERNANDEZ MI) }\end{array}$ & Mujer & $\begin{array}{l}\text { Universidad de } \\
\text { Extremadura }\end{array}$ & 3 \\
\hline $\begin{array}{l}\text { Carmen Valor } \\
\text { (VALOR C) }\end{array}$ & Mujer & $\begin{array}{l}\text { Universidad } \\
\text { Pontificia } \\
\text { Comillas }\end{array}$ & 3 \\
\hline $\begin{array}{l}\text { Nuria Villagra (VILLAGRA N) } \\
\text { Marcos Vizcaíno-González } \\
\text { (VIZCAINO-GONZALEZ M) }\end{array}$ & Mujer & $\begin{array}{l}\text { Complutense de } \\
\text { Madrid }\end{array}$ & 3 \\
\hline
\end{tabular}

Fuente: Elaboración propia a partir de los datos de WOS y Google Académico (enero 2020).

Es preciso indicar, que hasta el momento hemos centrado el análisis en los investigadores más productivos, pero no siempre son los más citados $\mathrm{y}$, por tanto, son los que más incidencia y repercusión han tenido en la literatura. Por ello a continuación mencionamos a los autores que han recibido más citas: 1) Donald Siegel de la Universidad de Arizona (3052 citas), 2) Abagail McWilliams de la Universidad de Ilinois en Chicago (2610 citas), 3) Tom J. Brown de la Universidad Estatal de Oklahoma (1545 citas), 4) Peter A. Dacin de la Universidad de Texas (1545 citas).

\subsection{Análisis de las principales publicaciones.}

En la tabla 8 se presentan los 12 artículos más citados entre 1993 - 2019 de acceso abierto. Excepto la publicación de los autores Turban y Greening (1997), las demás fueron artículos del año 2000 en adelante, lo que evidencia que la temática de investigación ha adquirido importancia en las últimas décadas.

Nueve de las doce publicaciones están basadas en estudios empíricos, para lo que emplearon importantes bases de datos de empresas. Entre ellas destaca la lista de las empresas más admiradas de Fortune. Los otros tres documentos consistieron en una revisión sistemática de la literatura. Además, cuatro publicaciones reforzaron sus análisis empleando encuestas a clientes o potenciales clientes, entre los que se hallan estudiantes universitarios.

En relación a la metodología estadística que han empleado, inicialmente, todas aquellas investigaciones empíricas, emplearon un estudio descriptivo, inferencia y correlaciones; posteriormente realizaron los análisis de regresión u otros modelos multivariantes para determinar las relaciones entre la RSC y sus elementos.

Todos los artículos coinciden en que la RSC es un elemento clave en la medición de la Reputación Empresarial. Además, con ella se construye una ventaja competitiva y diferencial en el mercado. Se ha resaltado el vínculo RSC-Reputación con el desempeño financiero, siempre que las actuaciones sean socialmente responsables, sinceras y debidamente comunicadas a los agentes de interés. Por último, también destaca como elemento la importancia de la RSC y la Reputación para la atracción y retención del talento. 
En la tabla 9 se presentan las 6 publicaciones con mayor número de citas de 2018 y 2019 (3 artículos de cada año). Solo uno, de los seis estudios recogidos en la tabla, consistió en una revisión de la literatura (Serra-Cantallops, Peña-Miranda y MartorellCunill), el resto realizaron estudios empíricos empleado bases de datos sobre empresas o encuestas a consumidores.

\section{TABLA 8: ANÁLISIS DE LOS ARTÍCULOS MÁS CITADOS ENTRE 1993 Y 2019 DE ACCESO ABIERTO}

\begin{tabular}{|c|c|c|c|}
\hline Título & $\begin{array}{l}\text { Corporate social } \\
\text { responsibility: A theory of } \\
\text { the firm perspective }\end{array}$ & $\begin{array}{c}\text { Corporate social performance } \\
\text { and organizational } \\
\text { attractiveness to prospective } \\
\text { employees }\end{array}$ & $\begin{array}{l}\text { Corporate social } \\
\text { responsibility and } \\
\text { resource-based } \\
\text { perspectives }\end{array}$ \\
\hline Citas & 2308 & 1196 & 509 \\
\hline $\begin{array}{l}\text { Personas } \\
\text { autoras }\end{array}$ & $\begin{array}{l}\text { Abagail McWilliams, } \\
\text { Donald Siegel }\end{array}$ & $\begin{array}{l}\text { Daniel B. Turban; Daniel W. } \\
\text { Greening }\end{array}$ & $\begin{array}{lr}\text { Manuel } & \text { Branco } \\
\text { Castelo; Lucia Lima } \\
\text { Rodrigues }\end{array}$ \\
\hline Género & 1 hombre, 1 mujer & 2 hombres & 1 hombre, 1 mujer \\
\hline $\begin{array}{l}\text { Año de } \\
\text { publicación }\end{array}$ & 2001 & 1997 & 2006 \\
\hline Revista & $\begin{array}{l}\text { Academy of Management } \\
\text { Review }\end{array}$ & $\begin{array}{l}\text { Academy of Management } \\
\text { Journal }\end{array}$ & $\begin{array}{l}\text { Journal of Business } \\
\text { Ethics }\end{array}$ \\
\hline Muestra & $\begin{array}{l}\text { Artículos sobre empresas } \\
\text { que cotizan en bolsa }\end{array}$ & 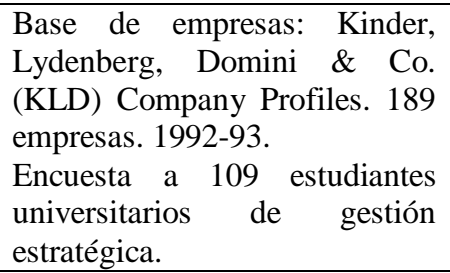 & Artículos científicos \\
\hline $\begin{array}{l}\text { Tratamiento } \\
\text { estadístico }\end{array}$ & Revisión de la literatura & Encuesta y análisis de regresión & 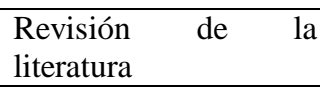 \\
\hline Conclusiones & $\begin{array}{l}\text { Existe un nivel "ideal" de } \\
\text { RSC, que los gerentes } \\
\text { pueden determinar mediante } \\
\text { un análisis de costo- } \\
\text { beneficio, y que existe una } \\
\text { relación neutral entre la } \\
\text { RSC y el desempeño } \\
\text { financiero. }\end{array}$ & $\begin{array}{l}\text { Las actuaciones en RSC } \\
\text { mejoran la Reputación y atraen } \\
\text { a trabajadores. } \\
\text { RSC es una potencial ventaja } \\
\text { competitiva }\end{array}$ & $\begin{array}{lr}\text { RSC es un valor } \\
\text { estratégico para la } \\
\text { empresa. } & \text { Atrae } \\
\text { mejores empleados, } \\
\text { aumentarar } \\
\text { motivación, moral, } \\
\text { compromiso y lealtad }\end{array}$ \\
\hline $\begin{array}{l}\text { Relación } \\
\text { entre RSC y } \\
\text { Reputación }\end{array}$ & $\begin{array}{l}\text { Los atributos de RSC se } \\
\text { pueden usar para construir o } \\
\text { mantener un Reputación de } \\
\text { calidad. }\end{array}$ & $\begin{array}{l}\text { La RSC de las empresas está } \\
\text { relacionado positivamente con } \\
\text { su Reputación y su atractivo } \\
\text { para los trabajadores. }\end{array}$ & $\begin{array}{l}\text { Los beneficios } \\
\text { externos de la RSC } \\
\text { están relacionados con } \\
\text { su efecto en la } \\
\text { Reputación } \\
\text { corporativa. }\end{array}$ \\
\hline Título & $\begin{array}{c}\text { Building corporate } \\
\text { associations: Consumer } \\
\text { attributions for corporate } \\
\text { socially responsible } \\
\text { programs }\end{array}$ & $\begin{array}{l}\text { The effect of corporate social } \\
\text { responsibility (CSR) activities } \\
\text { on companies with bad } \\
\text { reputations }\end{array}$ & $\begin{array}{c}\text { The relationship } \\
\text { between corporate } \\
\text { social performance, } \\
\text { and organizational } \\
\text { size, financial } \\
\text { performance, and } \\
\text { environmental } \\
\text { performance: An } \\
\text { empirical } \\
\text { examination } \\
\end{array}$ \\
\hline Citas & 505 & 416 & 391 \\
\hline $\begin{array}{l}\text { Personas } \\
\text { autoras }\end{array}$ & $\begin{array}{l}\text { Pam Scholder Ellen; } \\
\text { Deborah J. Webb; Lois A. } \\
\text { Mohr }\end{array}$ & $\begin{array}{l}\text { Yeosun Yoon; Zeynep Gürhan- } \\
\text { Canli; Norber Schwarz }\end{array}$ & $\begin{array}{l}\text { Peter A. Stanwick; } \\
\text { Sarah D. Stanwick }\end{array}$ \\
\hline Género & 3 mujeres & 1 hombre, 2 mujeres & 1 hombre, 1 mujer \\
\hline
\end{tabular}


Sánchez-Torné, I., Morán-Álvarez, J. C. y Pérez-Lopez, J. A.

\begin{tabular}{|c|c|c|c|}
\hline $\begin{array}{l}\text { Año de } \\
\text { publicación }\end{array}$ & 2006 & 2006 & 1998 \\
\hline Revista & $\begin{array}{l}\text { Journal of the Academy of } \\
\text { Marketing Science }\end{array}$ & $\begin{array}{l}\text { Journal of } \quad \text { Consumer } \\
\text { Psychology }\end{array}$ & $\begin{array}{l}\text { Journal of Business } \\
\text { Ethics }\end{array}$ \\
\hline Muestra & $\begin{array}{lr}281 & \text { estudiantes } \\
\text { universitarios (19-52 años) }\end{array}$ & 139 estudiantes universitarios & $\begin{array}{l}111 \text { empresas } \\
\text { incluidas en la lista } \\
\text { Fortune y según la } \\
\text { Agencia de Protección } \\
\text { Ambiental de Estados } \\
\text { Unidos estaban entre } \\
\text { las más contaminantes. } \\
1987 \text { - 1992. }\end{array}$ \\
\hline $\begin{array}{l}\text { Tratamiento } \\
\text { estadístico }\end{array}$ & $\begin{array}{l}\text { Cualitativo } \rightarrow \text { Entrevistas } \\
\text { Cuantitativo } \rightarrow \text { Modelo de } \\
\text { multivariante }\end{array}$ & $\begin{array}{l}\text { Experimento: } 3 \text { grupos que } \\
\text { analizar situaciones diferentes } \\
\text { de RSC de empresas } \\
\text { ANOVA }\end{array}$ & $\begin{array}{l}\text { Análisis descriptivo, } \\
\text { correlación, análisis de } \\
\text { regresión. }\end{array}$ \\
\hline Conclusiones & \begin{tabular}{lr} 
tipos de & motivos con \\
respuesta & positiva: \\
estratégicos & y valores \\
sociales. & \\
2 tipos de & motivos con \\
respuesta & \multicolumn{2}{c}{ negativa: } \\
egocéntricos e interés de \\
terceros.
\end{tabular} & $\begin{array}{l}\text { Actividades de RSC eficaces: } \\
\text { consumidores atribuyen } \\
\text { motivos sinceros. } \\
\text { Actividades de RSC ineficaces: } \\
\text { consumidores atribuyen } \\
\text { ambigüedad en la sinceridad. }\end{array}$ & $\begin{array}{l}\text { Las actuaciones de } \\
\text { RSC de una empresa se } \\
\text { ven afectadas por el } \\
\text { tamaño de la empresa, } \\
\text { el nivel de rentabilidad } \\
\text { de la empresa y la } \\
\text { cantidad de emisiones } \\
\text { de contaminación } \\
\text { emitidas por la } \\
\text { empresa. }\end{array}$ \\
\hline $\begin{array}{l}\text { Relación } \\
\text { entre RSC y } \\
\text { Reputación }\end{array}$ & $\begin{array}{l}\text { La RSC es clave para } \\
\text { construir la Reputación de } \\
\text { las empresas y crear una } \\
\text { ventaja diferencial }\end{array}$ & $\begin{array}{l}\text { Aunque la empresa tenga una } \\
\text { elevada Reputación } \\
\text { empresarial, esta se ve afectada } \\
\text { negativamente si realiza } \\
\begin{array}{l}\text { actuaciones RSC son poco } \\
\text { sinceras. }\end{array}\end{array}$ & $\begin{array}{l}\text { Las organizaciones } \\
\text { con alta valoración en } \\
\text { su Reputación también } \\
\text { son proactivas con el } \\
\text { medio ambiente. }\end{array}$ \\
\hline Título & $\begin{array}{c}\text { The Impact of Board } \\
\text { Diversity and Gender } \\
\text { Composition on } \\
\text { Corporate Social } \\
\text { Responsibility and Firm } \\
\text { Reputation } \\
\end{array}$ & $\begin{array}{c}\text { Corporate Social } \\
\text { Responsibility as a Conflict } \\
\text { Between Shareholders }\end{array}$ & $\begin{array}{c}\text { The Impact of } \\
\text { Corporate Social } \\
\text { Responsibility on } \\
\text { Firm Value: The } \\
\text { Role of Customer } \\
\text { Awareness } \\
\end{array}$ \\
\hline Citas & 382 & 367 & 361 \\
\hline $\begin{array}{l}\text { Personas } \\
\text { autoras }\end{array}$ & $\begin{array}{l}\text { Stephen Bear; Noushi } \\
\text { Rahman; Corinne Post }\end{array}$ & Amir Barnea; Amir Rubin & $\begin{array}{lr}\text { Henri } & \text { Servaes } \\
\text { (Servaes, Henri); Ane } \\
\text { Tamayo } \\
\text { Ane) }\end{array}$ \\
\hline Género & 1 mujer, 2 hombres & 2 hombres & 1 mujer, 1 hombre \\
\hline $\begin{array}{l}\text { Año de } \\
\text { publicación }\end{array}$ & 2010 & 2010 & 2013 \\
\hline Revista & Journal of Business Ethics & Journal of Business Ethics & Management Science \\
\hline Muestra & $\begin{array}{l}51 \text { empresas de la industria } \\
\text { médica dentro de la Fortune } \\
2009 .\end{array}$ & $\begin{array}{lcc}\text { Índice } & \text { Russell. } & 3000 \\
\text { corporaciones EEUU } & \end{array}$ & $\begin{array}{lr}\text { KLD Research } & \text { and } \\
\text { Analytics, } & \text { Inc. } \\
\text { Estadísticas } & \text { de } \\
\text { Compustat } & \\
\text { 1991-2005. } & 2000 \\
\text { empresas. } & \\
\end{array}$ \\
\hline $\begin{array}{l}\text { Tratamiento } \\
\text { estadístico }\end{array}$ & $\begin{array}{l}\text { Análisis de correlación y } \\
\text { análisis de regresión. }\end{array}$ & $\begin{array}{l}\text { Diferencia de medias, análisis } \\
\text { multivariante, análisis probit }\end{array}$ & $\begin{array}{l}\text { Estudio longitudinal. } \\
\text { Análisis descriptivo, } \\
\text { correlaciones y análisis } \\
\text { de regresión }\end{array}$ \\
\hline Conclusiones & $\begin{array}{l}\text { A mayor número de mujeres } \\
\text { en la junta directiva las } \\
\text { actuaciones de RSC tienen } \\
\text { mayor apoyo. }\end{array}$ & $\begin{array}{l}\text { La política de RSC puede } \\
\text { generar conflicto entre los } \\
\text { accionistas, ya que el dinero } \\
\text { destinado a RSC se resta de los } \\
\text { beneficios. }\end{array}$ & $\begin{array}{l}\text { Es necesario la } \\
\text { publicidad de la RSC } \\
\text { para que los clientes } \\
\text { tomen conciencia de } \\
\text { ellas. }\end{array}$ \\
\hline
\end{tabular}




\begin{tabular}{|c|c|c|c|}
\hline $\begin{array}{l}\text { Relación } \\
\text { entre RSC y } \\
\text { Reputación }\end{array}$ & $\begin{array}{l}\text { El porcentaje de mujeres en } \\
\text { la junta directiva se implica } \\
\text { una mejor Reputación de la } \\
\text { empresa }\end{array}$ & $\begin{array}{l}\text { La Reputación de algunos } \\
\text { accionistas de relieve puede } \\
\text { verse afectada por las } \\
\text { actuaciones en RSC }\end{array}$ & $\begin{array}{l}\text { Para que las RSC } \\
\text { generen valor en la } \\
\text { empresa, su } \\
\text { Reputación debe estar } \\
\text { alineada con su RSC. }\end{array}$ \\
\hline Título & $\begin{array}{c}\text { Environmental } \\
\text { marketing: A source of } \\
\text { reputational, competitive, } \\
\text { and financial advantage }\end{array}$ & $\begin{array}{l}\text { Family firms and social } \\
\text { responsibility: Preliminary } \\
\text { evidence from the S\&P } 500\end{array}$ & $\begin{array}{c}\text { Corporate reputation } \\
\text { and social } \\
\text { performance: The } \\
\text { importance of fit } \\
\end{array}$ \\
\hline Citas & 341 & 340 & 313 \\
\hline $\begin{array}{l}\text { Personas } \\
\text { autoras }\end{array}$ & $\begin{array}{l}\text { Morgan P. Miles; Jeffrey G. } \\
\text { Covin }\end{array}$ & $\begin{array}{l}\text { W. Gibb Dyer Jr.; David A, } \\
\text { Whetten }\end{array}$ & $\begin{array}{l}\text { Stephen J. Brammer; } \\
\text { Stephen Pavelin }\end{array}$ \\
\hline Género & 2 hombres & 2 hombres & 2 hombres \\
\hline $\begin{array}{l}\text { Año de } \\
\text { publicación }\end{array}$ & 2002 & 2006 & 2003 \\
\hline Revista & Journal of Business Ethics & $\begin{array}{l}\text { Entrepreneurship Theory and } \\
\text { Practice }\end{array}$ & $\begin{array}{l}\text { journal of management } \\
\text { studies }\end{array}$ \\
\hline Muestra & Artículos científicos & $\begin{array}{l}\text { Base de datos S\&P 500. } 1991 \text { - } \\
\text { 2000. } 261 \text { empresas. }\end{array}$ & $\begin{array}{l}210 \text { empresas más } \\
\text { grandes de los } \\
\text { diferentes sectores } \\
\text { industriales } \\
\text { Encuesta: Empresas } \\
\text { más admiradas de } \\
\text { Gran Bretaña' de } \\
\text { Management Today, } \\
2002\end{array}$ \\
\hline $\begin{array}{l}\text { Tratamiento } \\
\text { estadístico }\end{array}$ & Revisión de la literatura & $\begin{array}{l}\text { Estudio longitudinal. Análisis } \\
\text { descriptivo, análisis de } \\
\text { regresión. }\end{array}$ & $\begin{array}{l}\text { Estudio descriptivo, } \\
\text { correlaciones, análisis } \\
\text { de regresión }\end{array}$ \\
\hline Conclusiones & 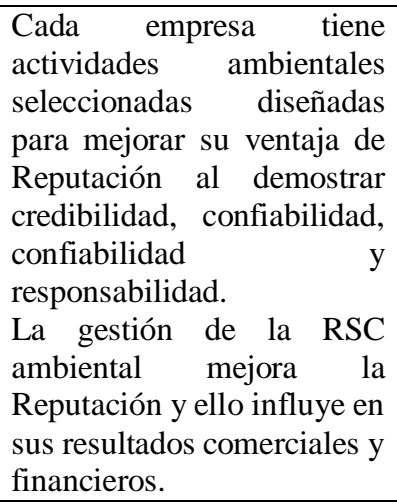 & $\begin{array}{l}\text { Los gerentes o propietarios de } \\
\text { las empresas familiares, al estar } \\
\text { relacionados directamente con } \\
\text { esta, pueden estar más } \\
\text { predispuestos a realizar } \\
\text { actuaciones de RSC que } \\
\text { aquellos gerentes no vinculados } \\
\text { con la empresa. }\end{array}$ & $\begin{array}{l}\text { El sector industrial } \\
\text { modera la relación } \\
\text { entre el desempeño } \\
\text { social y la Reputación, } \\
\text { de modo que la } \\
\text { relación es más fuerte } \\
\text { en sectores que están } \\
\text { asociados con } \\
\text { problemas sociales y } \\
\text { ambientales } \\
\text { importantes. }\end{array}$ \\
\hline $\begin{array}{l}\text { Relación } \\
\text { entre RSC y } \\
\text { Reputación }\end{array}$ & $\begin{array}{l}\text { La acción de marketing } \\
\text { ambiental de una empresa es } \\
\text { un recurso para gestionar la } \\
\text { Reputación corporativa. }\end{array}$ & $\begin{array}{l}\text { Las empresas familiares pueden } \\
\text { ser actores socialmente } \\
\text { responsables para proteger su } \\
\text { imagen y Reputación }\end{array}$ & \begin{tabular}{lrr} 
Existe una & \multicolumn{2}{r}{ relación } \\
positiva entre & el \\
desempeño & social \\
corporativo & y & la \\
Reputación. & & \\
\end{tabular} \\
\hline
\end{tabular}


TABLA 9: ARTÍCULOS PUBLIBLICADOS EN 2018 Y 2019 MÁS CITADOS EN RSC Y REPUTACIÓN DE ACCESO ABIERTO

\begin{tabular}{|c|c|c|c|}
\hline Título & $\begin{array}{l}\text { Does corporate social } \\
\text { responsibility affect } \\
\text { information } \\
\text { asymmetry? }\end{array}$ & $\begin{array}{c}\text { Effects of corporate social } \\
\text { responsibility on corporate } \\
\text { financial performance: A } \\
\text { competitive-action } \\
\text { perspective }\end{array}$ & $\begin{array}{c}\text { Progress in research on } \\
\text { CSR and the hotel } \\
\text { industry (2006-2015) }\end{array}$ \\
\hline Citas & 37 & 33 & 23 \\
\hline $\begin{array}{l}\text { Personas } \\
\text { autoras }\end{array}$ & $\begin{array}{l}\text { Jinhua Cui, Hoje Jo y } \\
\text { Haejung } \mathrm{Na}\end{array}$ & $\begin{array}{l}\text { Kwang-Ho Kim, Min Chung } \\
\text { Kim y Cuili Qian }\end{array}$ & $\begin{array}{l}\text { Antoni Serra-Cantallops, } \\
\text { David D. Peña-Miranda , } \\
\text { José Ramón-Cardona y } \\
\text { Onofre Martorell-Cunill }\end{array}$ \\
\hline Género & 2 mujer, 1 hombre & 1 hombre, 2 mujer & 4 hombres \\
\hline $\begin{array}{l}\text { Año de } \\
\text { publicación }\end{array}$ & 2018 & 2018 & 2018 \\
\hline Revista & $\begin{array}{l}\text { Journal of Business } \\
\text { Ethics }\end{array}$ & Journal of Management & $\begin{array}{ll}\text { Cornell } & \text { Hospitality } \\
\text { Quarterly } & \\
\end{array}$ \\
\hline Muestra & $\begin{array}{l}\text { Base de datos: 1) Kinder, } \\
\text { Lydenberg y Domini, 2) } \\
\text { Compustat, 3) Centro de } \\
\text { Investigación en Precios } \\
\text { de Seguridad. } 1991- \\
2010\end{array}$ & $\begin{array}{l}113 \text { empresas de la industria } \\
\text { de software de Estados Unidos } \\
\text { que cotizan en bolsa. } 2000 \text { y } \\
2005 \text {. }\end{array}$ & $\begin{array}{l}48 \text { Artículos científicos } \\
\text { industria hotelera }\end{array}$ \\
\hline $\begin{array}{l}\text { Tratamiento } \\
\text { estadístico }\end{array}$ & $\begin{array}{l}\text { Análisis descriptivo, } \\
\text { correlaciones, modelo de } \\
\text { regresión }\end{array}$ & $\begin{array}{l}\text { Análisis } \begin{array}{l}\text { descriptivo, } \\
\text { correlaciones, modelo de } \\
\text { regresión }\end{array} \\
\end{array}$ & $\begin{array}{l}\text { Revisión de la literatura } \\
\text { (2006-2015) }\end{array}$ \\
\hline Conclusiones & $\begin{array}{l}\text { Las empresas que } \\
\text { realizan actuaciones en } \\
\text { RSC reduce la asimetría } \\
\text { de información respecto a } \\
\text { sus clientes }\end{array}$ & $\begin{array}{l}\text { La RSC mejoran el } \\
\text { rendimiento financiero de la } \\
\text { empresa cuando la empresa es } \\
\text { activa en la búsqueda de } \\
\text { satisfacer a los clientes } \\
\text { Las actuaciones socialmente } \\
\text { irresponsables mejorar el } \\
\text { desempeño financiero de la } \\
\text { empresa cuando esta no es } \\
\text { activa en satisfacer las } \\
\text { necesidades de los clientes. }\end{array}$ & $\begin{array}{l}\text { La literatura no muestra un } \\
\text { consenso en las reacciones } \\
\text { de los consumidores ante } \\
\text { las actuaciones en RSC y } \\
\text { cómo estas se vinculan } \\
\text { positivamente con el } \\
\text { desempeño financiero. }\end{array}$ \\
\hline $\begin{array}{l}\text { Relación } \\
\text { entre RSC y } \\
\text { Reputación }\end{array}$ & $\begin{array}{l}\text { La RSC sirve construir y } \\
\text { mantener la Reputación } \\
\text { de la empresa. }\end{array}$ & $\begin{array}{l}\text { Si la empresa realiza } \\
\text { actuaciones socialmente } \\
\text { irresponsable, pueden dañar la } \\
\text { Reputación y las relaciones de } \\
\text { la empresa con las diferentes } \\
\text { partes interesadas. }\end{array}$ & $\begin{array}{l}\text { Si las partes interesadas } \\
\text { conocen las actuaciones en } \\
\text { RSC, tiene un efecto } \\
\text { indirecto en la Reputación } \\
\text { de la empresa. }\end{array}$ \\
\hline Título & $\begin{array}{c}\text { The process model of } \\
\text { corporate social } \\
\text { responsibility (CSR) } \\
\text { Communication: CSR } \\
\text { Communication and its } \\
\text { relationship with } \\
\text { consumers' CSR } \\
\text { knowledge, trust, and } \\
\text { corporate reputation } \\
\text { perception }\end{array}$ & $\begin{array}{c}\text { What Makes CSR } \\
\text { Communication Lead to } \\
\text { CSR Participation? Testing } \\
\text { the Mediating Effects of } \\
\text { CSR Associations, CSR } \\
\text { Credibility, and } \\
\text { Organization-Public } \\
\text { Relationships }\end{array}$ & $\begin{array}{l}\text { From Doing Good to } \\
\text { Looking Even Better: } \\
\text { The Dynamics of CSR } \\
\text { and Reputation }\end{array}$ \\
\hline Citas & 21 & 11 & 11 \\
\hline $\begin{array}{l}\text { Personas } \\
\text { autoras }\end{array}$ & Sora Kim & $\begin{array}{lll}\text { Sun Young Lee; } & \text { Weiwu } \\
\text { Zhang; Alan Abitbol } & \\
\end{array}$ & $\begin{array}{l}\text { Carol-Ann Tetrault Sirsly, } \\
\text { Elena Lvina }\end{array}$ \\
\hline Género & 1 mujer & 1 mujer, 2 hombres & 2 mujeres \\
\hline $\begin{array}{l}\begin{array}{l}\text { Año de } \\
\text { publicación }\end{array} \\
\end{array}$ & 2019 & 2019 & 2019 \\
\hline
\end{tabular}




\begin{tabular}{|c|c|c|c|}
\hline Revista & $\begin{array}{l}\text { Journal of Business } \\
\text { Ethics }\end{array}$ & Journal of Business Ethics & Business \& Society \\
\hline Muestra & $\begin{array}{l}930 \text { consumidores de } \\
\text { Estados Unidos }\end{array}$ & $\begin{array}{l}394 \text { clientes de una cadena de } \\
\text { tiendas de comestibles (HEB). } \\
\text { Texas }\end{array}$ & $\begin{array}{l}285 \text { empresas de la base de } \\
\text { datos KLD y Fortune. } \\
\text { Estados Unidos. } 2002 \text { - } \\
2007\end{array}$ \\
\hline $\begin{array}{l}\text { Tratamiento } \\
\text { estadístico }\end{array}$ & $\begin{array}{l}\text { Encuesta. Análisis } \\
\text { descriptivo, modelo de } \\
\text { ecuaciones estructurales. }\end{array}$ & $\begin{array}{l}\text { Encuesta. } \\
\text { Modelo de ecuaciones } \\
\text { estructurales }\end{array}$ & $\begin{array}{lr}\text { Análisis } & \text { descriptivo, } \\
\text { correlaciones, ecuaciones } \\
\text { estructurales }\end{array}$ \\
\hline Conclusiones & $\begin{array}{l}\text { Importancia de la } \\
\text { comunicación de las } \\
\text { actuaciones en RSC para } \\
\text { que los consumidores } \\
\text { tengan conciencia de ello, } \\
\text { eso conlleva a un } \\
\text { aumento de la confianza } \\
\text { en la empresa. }\end{array}$ & $\begin{array}{l}\text { El nivel de uso de todos los } \\
\text { canales de comunicación de } \\
\text { los encuestados, excepto los } \\
\text { informes de RSC, se relacionó } \\
\text { positivamente con su nivel de } \\
\text { conciencia de RSC sobre la } \\
\text { compañía. }\end{array}$ & $\begin{array}{l}\text { La RSC puede predecir un } \\
\text { cambio en la Reputación. } \\
\text { Las mejoras en la RSC } \\
\text { deben ser constantes para } \\
\text { no estancar la Reputación. }\end{array}$ \\
\hline $\begin{array}{l}\text { Relación } \\
\text { entre RSC y } \\
\text { Reputación }\end{array}$ & $\begin{array}{l}\text { Cuando los consumidores } \\
\text { perciben que la RSC tiene } \\
\text { un objetivo de } \\
\text { autopromoción, afecta } \\
\text { negativamente a la } \\
\text { Reputación corporativa. }\end{array}$ & $\begin{array}{l}\text { Las actividades de RSC de las } \\
\text { empresas y sus esfuerzos de } \\
\text { comunicación, que se basan en } \\
\text { beneficios mutuos, como la } \\
\text { generación de valor social y } \\
\text { una Reputación corporativa } \\
\text { favorable }\end{array}$ & $\begin{array}{l}\text { La Reputación es una } \\
\text { ventaja competitiva. } \\
\text { La rapidez con la que } \\
\text { puede cambiar la } \\
\text { Reputación de una } \\
\text { empresa depende del } \\
\text { sector al que pertenece. }\end{array}$ \\
\hline
\end{tabular}

Se sigue usando una metodología estadística descriptiva y correlaciones, pero se incluyen los modelos de ecuaciones estructurales como técnica principal para analizar las relaciones entre los elementos de la RSC y la Reputación.

A nivel teórico, se refuerzan los hallazgos de la relación entre RSC y Reputación, ambas deben de tener una implicación personal de la empresa para que realmente se constituya una ventaja competitiva.

Las áreas en relación a la temática de investigación son principalmente del campo de la empresa y los negocios, pero la comunicación y el marketing adquieren cada vez más protagonismo.

En ambas tablas, en un análisis desde una perspectiva de género, se comprueba que las investigadoras están presentes casi en el mismo número que los investigadores.

\section{CONCLUSIONES}

Este artículo se encuadra dentro de las investigaciones sobre la RSC y Reputación. Se han marcado 5 objetivos dirigidos a evidenciar el estado de esos temas en la literatura entre 1993 y 2019.

Tanto la evolución sobre el volumen de publicaciones, como el número de citas en relación a ellos ha aumentado exponencialmente, lo que pone de relieve que la RSC y la Reputación son de interés creciente y todavía no suponen una temática agotada.

Las revistas que incluyen más artículos en sus números sobre RSC y Reputación y que, por tanto, son aquellas a las que primero hay que dirigir los envíos de manuscrito fueron: Journal of Business Ethics, Corporate Social Responsibility and Environmental Management, Corporate Reputation Review, Social Responsibility Journal y Sustainability. Todas estas revistas publican en inglés (Reino Unido y América).

También existen revistas que publican artículos en español, pero el número de artículos sobre RSC y Reputación es menor que en las mencionadas anteriormente, como 
fueron: Estudios Gerenciales, Revista Universidad empresa, Retos-Revista de Ciencias de la Administración y Economía, Dimensión Empresarial, Revista de Contabilidad, Revista Cicag, CIRIEC-España revista de Economía publica social y cooperativa, Revista Perspectiva Empresarial, Revista de Estudios Empresariales-Segunda época, REVESCORevista de Estudios Cooperativos.

Se entiende que a la temática de investigación RSC y Reputación es de interés transversal, lo que ha derivado que el 86,65 por cien de los autores solo ha publicado un artículo sobre ello. Se ha evidenciado que existen investigadores relevantes en estas materias, así destacamos a: John Peloza (10 artículos y 412 citas) de la Universidad de Kentucky (Estados Unidos), Su Lujun de la Unversidad Central del Sur en China (9 artículos y 117 citas) Isabel María García Sánchez de la Universidad de Salamanca en España (9 artículos y 196 citas).

En relación al análisis de los autores, entre aquellos que publicaron al menos 5 investigaciones, solo el 41,67 por cien de las personas autoras fueron mujeres (10). A ellas les corresponde el 39,86 por cien de los artículos, pero estos solo recibieron el 18,70 por cien de las citas. Si centramos este análisis dentro del territorio español (con 3 o más publicaciones) los datos son más equitativos, el 53,85 por cien de las personas autoras fueron mujeres, estas abarcaron el 56,76 por cien de las publicaciones, pero solo supusieron el 40,20 por cien de las citas. En este caso sería preciso ahondar en esta diferencia de género con el fin de aclarar sus motivos. La Unión Europea es la región que muestra más personas investigadoras (41,67 por cien) en RSC y Reputación. Aunque es la segunda en volumen de publicaciones, por delante se encuentra Estados Unidos (21,15 por cien).

Las autorías españolas ocupan un puesto relevante, especialmente aquellas pertenecen a las universidades de Cantabria y Salamanca, entre las que destacan Isabel María García Sánchez de la Universidad de Salamanca fue la autora más productiva (9 artículos y 196 citas) y Ladislao Luna Sotorrio de la Universidad de Cantabria (7 artículos y 217 citas).

Mayoritariamente los artículos analizados se realizaron en el ámbito empírico, empleado para ello bases de empresas como: lista de las empresas más admiradas de Fortune, Kinder, Lydenberg, Domini \& Co. (KLD) Company Profiles, Índice Russell. 3000, Empresas más admiradas de Gran Bretaña' de Management Today. Otros estudios extrajeron la información a través de encuestas, bien sea clientes de ciertas empresas o a colectivos más generales como son los estudiantes universitarios.

La metodología estadística empleada para demostrar las relaciones entre RSC, sus elementos y Reputación fue modelos de regresión y ecuaciones estructurales.

Se ha evidenciado que existe coincidencia en la documentación analizada sobre que, si las actuaciones en RSC se perciben de manera sincera e integrada en los valores de la empresa, mejora la Reputación empresarial. Lo cual supone una ventaja competitiva en el mercado que afianza clientes, atrae y retiene el talento. Dentro de los aspectos de la RSC la protección del medio ambiente cobra fuerza, así que las empresas pueden ver una oportunidad de negocio en la elaboración de productos ecoinnovadores (Villena Manzanares y Galiano Coronil, 2017).

Eminentemente la temática de investigación RSC y Reputación se ubica en los campos de la gestión empresarial, cobra cada vez más presencia en la comunicación y el marketing.

Con esta investigación se ha pretendido elaborar un artículo útil para la comunidad científica, donde pueda reconocer las principales revistas de publicación y autorías. 
Además, este documento ofrece un soporte científico para corroborar la relevancia de las investigaciones en RSC y Reputación, con un interés creciente.

Dentro de las limitaciones del artículo se encuentra la generalidad del mismo, puesto que no se ha centrado en un aspecto específico de la RSC. Esto es debido al interés por abarcar al conjunto de autorías dedicadas a investigar sobre ese la temática de investigación. Por otro lado, el ámbito de la responsabilidad social se extiende a otras instituciones que se han dejado al margen al incorporar la palabra "corporate" en la ecuación de búsqueda, atiéndase a la responsabilidad social en instituciones públicas, asociaciones, fundaciones, entre otras.

A tenor de los resultados evidenciados, dentro de las futuras líneas de investigación se encontraría la necesidad de completar este estudio con un análisis de redes sobre los investigadores europeo. Autores como Batagelj y Cerinšek (2013) han puesto de manifiesto la utilidad de estos análisis en los estudios bibliométrico y de revisión de la literatura. Por otro lado, el auge de las redes sociales como altavoz de la opinión de los clientes ha supuesto que las empresas deben gestionar dichas opiniones puesto que inciden en su reputación, aparece así el concepto de Reputación on line (Sánchez Jiménez, Fernández Alles y Mier-Terán Franco, 2018). Teniendo presente la trayectoria ascendente de las redes sociales y web de opinión, la gestión de la Reputación online supone una nueva línea de investigación por explotar.

\section{BIBLIOGRAFÍA}

Aguilera-Caracuel, J., y Guerrero-Villegas, J. (2018): "How corporate social responsibility helps MNEs to improve their reputation. The moderating effects of geographical diversification and operating in developing regions", Corporate Social Responsibility and Environmental Management, vol. 25, nº4, pp. 355-372. https://doi.org/10.1002/csr.1465.

Aksak, E. O., Ferguson, M. A., y Duman, S. A. (2016): “Corporate social responsibility and CSR fit as predictors of corporate reputation: A global perspective”, Public Relations Review, vol. 42, $\quad \mathrm{n}^{\circ} \quad 1, \quad$ pp. $\quad 79-81$. https://doi.org/10.1016/j.pubrev.2015.11.004.

Almeida, M. D. G. M. C., y Coelho, A. F. M. (2019): “The Antecedents of Corporate Reputation and Image and Their Impacts on Employee Commitment and Performance: The Moderating Role of CSR”, Corporate Reputation Review, vol. 22, no1, pp. 10-25. https://doi.org/10.1057/s41299-018-0053-8.

Aramburu, I. A., y Pescador, I. G. (2019): “The effects of corporate social responsibility on customer loyalty: The mediating effect of reputation in cooperative banks versus commercial banks in the Basque country”, Journal of Business Ethics, vol. 154, nº3, pp. 701-719.

Ardanuy Baró, J, (2012): "Breve introducción a la bibliometría”, La base de datos scopus y otros e-recursos del CBUES como instrumento de gestión de la actividad investigadora; 1.

Arguimbau Vivó, L., Fuentes Pujol, E. y Gallifa Calatayud, M, (2013): “Una década de investigación documental sobre cienciometría en España: Análisis de los artículos de la base de datos ISOC (2000-2009)", Revista Española de Documentación Científica, vol. 36, n², pp. 1-9.

Bae, J., Choi, W., y Lim, J. (2020): “Corporate social responsibility: An umbrella or a puddle on a rainy day? Evidence surrounding corporate financial misconduct”, European Financial Management, vol. 26, pp. 77-117 https://doi.org/10.1111/eufm.12235. 
Batagelj, V., y Cerinšek, M, (2013): “On bibliographic networks”, Scientometrics, vol. 96, n³, pp. 845-864. https://doi.org/10.1007/s11192-012-0940-1.

Bear, S., Rahman, N., y Post, C. (2010): "The impact of board diversity and gender composition on corporate social responsibility and firm reputation”, Journal of business ethics, vol. 97, $\mathrm{n}^{\circ}$ 2, pp. 207-221. 10.1007/s10551-010-0505-2.

Bennett, R., y Gabriel, H. (2001): "Reputation, trust and supplier commitment: the case of shipping company/seaport relations”, Journal of business \& industrial marketing, vol. $\quad 16, \quad \mathrm{n}^{\circ} 6, \quad$ pp. $424-438$. https://doi.org/10.1108/EUM0000000006018.

Boccia, F., y Sarnacchiaro, P. (2018): "The impact of corporate social responsibility on consumer preference: A structural equation analysis”, Corporate Social Responsibility and Environmental Management, vol. 25, $\mathrm{n}^{\circ} 2$, pp. 151163. https://doi.org/10.1002/csr.1446.

Cagin, M. (2018): “The Importance of Social Responsibility Projects in Reputation Management: The Role of Public Relations”, Global Media Journal, vol. 8, pp. 229-239.

Cobo, M, J., López-Herrera, A, G., Herrera-Viedma, E., y Herrera, F. (2011): "Science mapping software tools: Review, analysis, and cooperative study among tools", Journal of the American Society for Information Science and Technology, vol. 62, nº7, pp. 1382-1402. https://doi.org/10.1002/asi.21525.

Comunicación de la Comisión relativa a la responsabilidad social de las empresas: una contribución empresarial al desarrollo sostenible /* COM/2002/0347 final */ https://eur-

lex.europa.eu/LexUriServ/LexUriServ.do?uri=CELEX:52002DC0347:ES:HTM L.

Cui, J., Jo, H., y Na, H. (2018): "Does corporate social responsibility affect information asymmetry?” Journal of Business Ethics, vol. 148, n³, pp. 549572. https://doi.org/10.1007/s10551-015-3003-8.

Ellen, P. S., Webb, D. J., y Mohr, L. A. (2006): "Building corporate associations: Consumer attributions for corporate socially responsible programs” Journal of the academy of Marketing Science, vol. 34, $\mathrm{n}^{0} 2$, pp. 147-157. https://doi.org/10.1177/0092070305284976.

Fernandez-Cano, A., Torralbo, M., y Vallejo, M. (2004): "Reconsidering Price's model of scientific growth: an overview”, Scientometrics, vol. 61, n³, pp. 301-321.

Fombrun, C. J. (1996): Reputation, Harvard Business School Press, Boston, MA.

Gómez García, F. (2008): "Responsabilidad social corporativa y performance financiero: treinta y cinco años de investigación empírica en busca de un consenso", Principios, vol. 11, pp., 5 -22.

Griffin, A. (2008): New strategies for reputation management: gaining control of issues, crises \& corporate social responsibility. Kogan Page Publishers.

Helm, S. (2007): "One reputation or many? Comparing stakeholders' perceptions of corporate reputation”, Corporate Communications: An International Journal, vol. 12, no3, pp. 238-254. https://doi.org/10.1108/13563280710776842.

Herremans, I. M., Akathaporn, P., y McInnes, M. (1993): “An investigation of corporate social responsibility reputation and economic performance" Accounting, organizations and society, vol. 18, $\mathrm{n}^{\circ}$ 7-8, pp. 587-604.

Kim, K. H., Kim, M., y Qian, C. (2018): "Effects of corporate social responsibility on corporate financial performance: A competitive-action perspective”, Journal of $\begin{array}{lllll}\text { Management, } & \text { vol. } & 44, & \mathrm{n}^{\circ} 3, & \text { pp. }\end{array}$ https://doi.org/10.1177/0149206315602530. 
Kim, S. (2019): “The process model of corporate social responsibility (CSR) communication: CSR communication and its relationship with consumers' CSR knowledge, trust, and corporate reputation perception”, Journal of Business Ethics, vol. 154, nº, pp. 1143-1159. https://doi.org/10.1007/s10551017-3433-6.

Kim, S. B., y Kim, D. Y. (2017): "Antecedents of corporate reputation in the hotel industry: The moderating role of transparency” Sustainability, vol. 9, nº6, pp. 951. https://doi.org/10.3390/su9060951.

Lee, S. Y., Zhang, W., y Abitbol, A. (2019): "What Makes CSR Communication Lead to CSR Participation? Testing the Mediating Effects of CSR Associations, CSR Credibility, and Organization-Public Relationships”, Journal of Business Ethics, vol. 157, n², pp. 413-429. https://doi.org/10.1007/s10551-017-3609-0.

Leiva, R., Ferrero, I., y Calderón, R. (2016): "Corporate reputation in the business ethics field: Its relation with corporate identity, corporate image, and corporate social responsibility” Corporate Reputation Review, vol. 19, nº4, pp. 299-315. https://doi.org/10.1057/s41299-016-0008-X.

Marquina, P., Arellano, R., y Velasquez, I. (2014): “A New Approach for Measuring Corporate Reputation” Revista de Administraçao de Empresas, vol. 54, nº1, pp. 53-66. https://doi.org/10.1590/S0034-759020140102.

McWilliams, A., y Siegel, D. (2001): "Corporate social responsibility: A theory of the firm perspective” Academy of management review, vol. 26, nº1, pp. 117-127.

Melo, T., y Garrido-Morgado, A. (2012): "Corporate reputation: A combination of social responsibility and industry" Corporate social responsibility and environmental management, vol. 19, $\mathrm{n}^{\circ} 1$, pp. 11-31. https://doi.org/10.1002/csr.260.

Moreno-Fernández, Á., y Fuentes-Lara, M. C. (2019): “"Engagement’y redes sociales. Análisis bibliométrico desde el ámbito científico de las relaciones públicas”. Trípodos, vol. 45, pp. 49-72.

Pritchard, A. (1969): "Statistical bibliography or bibliometrics", Journal of documentation, vol. 25, nº 4 , pp. 348-349.

Rueda, G., Gerdsri, P., y Kocaoglu, D,F, (2007): "Bibliometrics and social network analysis of the nanotechnology field”, In PICMET"07-2007 Portland International Conference on Management of Engineering \& Technology, pp, 2905-2911, IEEE.

Sánchez Jiménez, M. Ángel, Fernández Alles, M. T., y Mier-Terán Franco, J. J. (2018): "Revisión teórica del marketing en los medios sociales: antecedentes y estado de la cuestión” Revista de Estudios Empresariales. Segunda época, vol. 1, pp. 42-57. https://dx.doi.org/10.17561/ree.v2018n1.3.

Serra-Cantallops, A., Peña-Miranda, D. D., Ramón-Cardona, J., y Martorell-Cunill, O. (2018): "Progress in research on CSR and the hotel industry (20062015)” Cornell Hospitality Quarterly, vol. 59, nº 1 , pp. 15-38. https://doi.org/10.1177/1938965517719267.

Servaes, H., y Tamayo, A. (2013): “The impact of corporate social responsibility on firm value: The role of customer awareness” Management science, vol. 59, $\mathrm{n}^{\mathrm{o}}$ 5, pp. 1045-1061. https://doi.org/10.1287/mnsc.1120.1630.

Stanwick, P. A., y Stanwick, S. D. (1998): “The relationship between corporate social performance, and organizational size, financial performance, and environmental performance: An empirical examination” Journal of business ethics, vol. 17, $\mathrm{n}^{\circ} 2$, pp. 195-204. https://doi.org/10.1023/A:1005784421547. 
Tetrault Sirsly, C. A., y Lvina, E. (2019): "From doing good to looking even better: The dynamics of CSR and reputation” Business \& Society, vol. 58, $\mathrm{n}^{\mathrm{0}}$ 6, pp. 1234-1266. https://doi.org/10.1177/0007650315627996.

Toro, J. A. O., y Pavia, C. F. (2019): “The Effects of Branding Intangibles on Corporate Reputation”, Revista de comunicación, vol. 18, pp. 111-134. https://doi.org/10.26441/RC18.1-2019-A6

Turban, D. B., y Greening, D. W. (1997): "Corporate social performance and organizational attractiveness to prospective employees”, Academy of management journal, vol. 40, n⿳3, pp. 658-672.

Villena Manzanares, F., y Galiano Coronil, A. (2017): "El desarrollo urbano sostenible y sus implicaciones para las empresas y los territorios”, Revista De Estudios Empresariales. Segunda Época, vol.1. https://doi.org/10.17561/ree.v0i1.3185

Yoon, Y., Gürhan-Canli, Z., y Schwarz, N. (2006): "The effect of corporate social responsibility (CSR) activities on companies with bad reputations”, Journal of consumer psychology, vol. 16, $\mathrm{n}^{\circ} \quad 4, \quad$ pp. 377-390. https://doi.org/10.1207/s15327663jcp1604_9 